\title{
Nanostage Alloying of Metals in Liquid Phase
}

\author{
Deblina Roy ${ }^{1}$, Tarasankar Pal ${ }^{2 *}$ \\ ${ }^{1}$ Department of Chemistry, National Institute of Technology, Rourkela, Odisha, India \\ ${ }^{2}$ Department of Chemical Sciences, Auckland Park Kingsway Campus, University of Johannesburg, Johannesburg, South Africa \\ Email: ^tpal@chem.iitkgp.ac.in
}

How to cite this paper: Roy, D. and Pal, T. (2021) Nanostage Alloying of Metals in Liquid Phase. Advances in Chemical Engineering and Science, 11, 105-140. https://doi.org/10.4236/aces.2021.111008

Received: December 25, 2020

Accepted: January 26, 2021

Published: January 29, 2021

Copyright (C) 2021 by author(s) and Scientific Research Publishing Inc. This work is licensed under the Creative Commons Attribution International License (CC BY 4.0).

http://creativecommons.org/licenses/by/4.0/ (c) (i) Open Access

\begin{abstract}
Alloying of metals is known from antiquity. Alloy making i.e., homogenizing metals started in a "hit-or-miss" way. The $1^{\text {st }}$ alloy from copper $(\mathrm{Cu})$ and tin (Sn) was produced around $2500 \mathrm{BC}$ and from then Bronze Age began. Subsequently iron $(\mathrm{Fe})$ age started after the Bronze Age. Aluminium ( $\mathrm{Al}$ ) alloying was discovered much later because pure $\mathrm{Al}$ could not be recovered easily even though $\mathrm{Al}$ is the most abundant metal in the earth's crust. Refining of $\mathrm{Al}$ is a very difficult job because of its strong affinity towards oxygen. To ease alloying, melting points $(\mathrm{mp})$ of the individual constituents and reactivity of metal towards oxygen were the hurdles. Now understanding the thermodynamics of metal mixing has paved alloying. Periodic properties of elements concerning size, electronegativity, crystal structure, valency, lattice spacing, etc. are considered for alloying. In this feature article, more emphasis is given to Hume-Rothery rules in which the necessary parameters for alloying have been illustrated. Importantly standard electrode potential $\left(\mathrm{E}^{0}\right)$ values, eutectic, phase diagram, size-related strain in metals, etc. have been looked into in the present discussion. One elegant example is $\mathrm{Sn}-\mathrm{Pb}$ alloy, known as soft solder. Soft solder was in use for many years to connect metals and in electric circuitry. Low melting, flowability, and conductivity of soft solder had placed $\mathrm{Sn}-\mathrm{Pb}$ alloy a unique position in industries, laboratories and even in cottage industries. However, toxic $\mathrm{Pb}$ volatilizes during soldering and hence soft solder is banned almost in all countries. We felt the need for a viable alternative to obtain soldering material and then silver $(\mathrm{Ag})$ based highly conducting, an eco-friendly alloy of $\mathrm{Sn}$ resulted in from a high boiling liquid. The discovery engenders not only a new conducting soldering alloy but also a new concept of melting metals together. Furthermore, new ideas of alloying have been generalized at their nanostages from a suitable high boiling solvent.
\end{abstract}

\section{Keywords}

Alloy, Nanoparticles, Hume-Rothery Rules, Oriented Attachment, Ostwald Ripening, Digestive Ripening, Galvanic Replacement Reaction, Kirkendall 
Effect, Silicone Oil, High Entropy Alloys

\section{Introduction}

Need-based discoveries have gifted us to a civilized world. In general, pure metals have been exploited for the advancement of civilization. Impurities (within the metal) have given us many smart materials. The modern technological advancement relies not only on alloying but also on defect making in some cases with deliberate incorporation of controlled impurities. Alloying of metal has been preferred better to say started in a way to make harder materials for self-defense i.e., for weapon making [1].

Around $2500 \mathrm{BC}$, ancient civilization began to alloy $\mathrm{Cu}$ and $\mathrm{Sn}$ to make bronze. They found bronze to be much harder and durable than its ingredients. Bronze Age followed the Iron Age. Though $\mathrm{Fe}$ is the $4^{\text {th }}$ most abundant element in the earth's crust, its high $\mathrm{mp}\left(1538^{\circ} \mathrm{C}\right)$ restricts them to use it for alloying. Whereas $\mathrm{Sn}$ has low $\mathrm{mp}\left(239^{\circ} \mathrm{C}\right)$ and $\mathrm{Cu}$ has relatively moderate $\mathrm{mp}\left(1085^{\circ} \mathrm{C}\right)$, which encouraged them to alloy these two metals together [1] [2]. The main reason for the collapse of the Bronze Age was due to the shortage of Sn supply, which disrupted the trade route of $\mathrm{Sn}$ and forced them to seek an alternative to bronze. Since, Fe was cheaper, stronger, and lighter than Sn, so it was implemented in alloying.

Aluminium ( $\mathrm{Al}$ ) is the most abundant metal in the earth's crust but $\mathrm{Al}$ alloy was discovered much later. Due to the strong affinity of $\mathrm{Al}$ towards oxygen and very high $\mathrm{mp}$ of alumina $\left(2000^{\circ} \mathrm{C}\right)$, its extraction and subsequent alloying had to wait until the $20^{\text {th }}$ century [2]. Later on, scientists and engineers joined hands to apply thermodynamics for the technology to obtain $\mathrm{Al}$ alloys.

Now pure metals (prepared ex situ) and latter metallic compounds (in situ) have been explored for generalization of alloying technology for a wide number of metals and nonmetals, keeping an eye to the thermodynamics aspects of the participating elements. As a result, metal emerges with improved mechanical, thermal, electrical, corrosion resistance, and tensile strength. Metal alloying techniques have always given birth to newer methodologies like fusion [1], electro-deposition [1] [3], reduction [1], and powder metallurgy [1]. In so doing, innumerable useful alloys are obtained. Alloys even with internal strains may now be produced easily in the nanoregime of metal particles in high boiling liquids. This is a new proposition and altogether departure from the known concepts.

\section{Preparations}

There are in general two age-old methods such as melting [1] and ball milling [4] adopted for the preparation of alloys, discussed one after the other in the following paragraphs. However, ball milling and melting metals together with 
the idea of the phase diagram are age-old but important processes for making an alloy. To comprehend the different phases resulting from the different composition of alloys and to know the terminal solubility of the alloying elements, the idea of the phase diagram is very important. The phase has a certain chemical composition and a distinct type of interatomic bonding and rearrangement. Each phase within an alloy has its own chemical and physical properties. It governs the fabrication of alloys into a useful configuration. A Phase diagram shows what phases exist at equilibrium and what phase transformations we can expect when we change one of the parameters of the system. This phenomenon is well understood by the binary phase diagram of a silver $(\mathrm{Ag})$-gold $(\mathrm{Au})$ system, which is presented in Figure 1, which is a simple lens type structure. The diagram is composed of three distinct regions. At high temperature, there is a liquid solution, at low temperature, there is a solid solution with the FCC phase with complete miscibility and at lens shape, there exist both solid and liquid phases [5].

Alloying is done through melting different elements together as mentioned earlier. If the $\mathrm{mp}$ of a component metal is different from the other component metal with higher $\mathrm{mp}$, then the higher melting metal is melted first and subsequently the other component with a lower $\mathrm{mp}$ is allowed to add into the melt, in order to avoid the volatilization of low melting metal. This process is experimentally affirmed for brass (Cu- $\mathrm{Zn}$ alloy) production. Since $\mathrm{mp}$ of $\mathrm{Cu}$ is $1085^{\circ} \mathrm{C}$ whereas $\mathrm{Zn}$ melts at $419.5^{\circ} \mathrm{C}$ and boils at $907^{\circ} \mathrm{C}$. Therefore, if solid $\mathrm{Zn}$ and solid $\mathrm{Cu}$ are melted together then $\mathrm{Zn}$ will volatilize before homogenization [1]. So, both the metal components are well ground before melting and then melted for alloying. The molten mass is covered by powdered carbon to avoid oxidation of the molten alloy components because they are very reactive to the surrounding

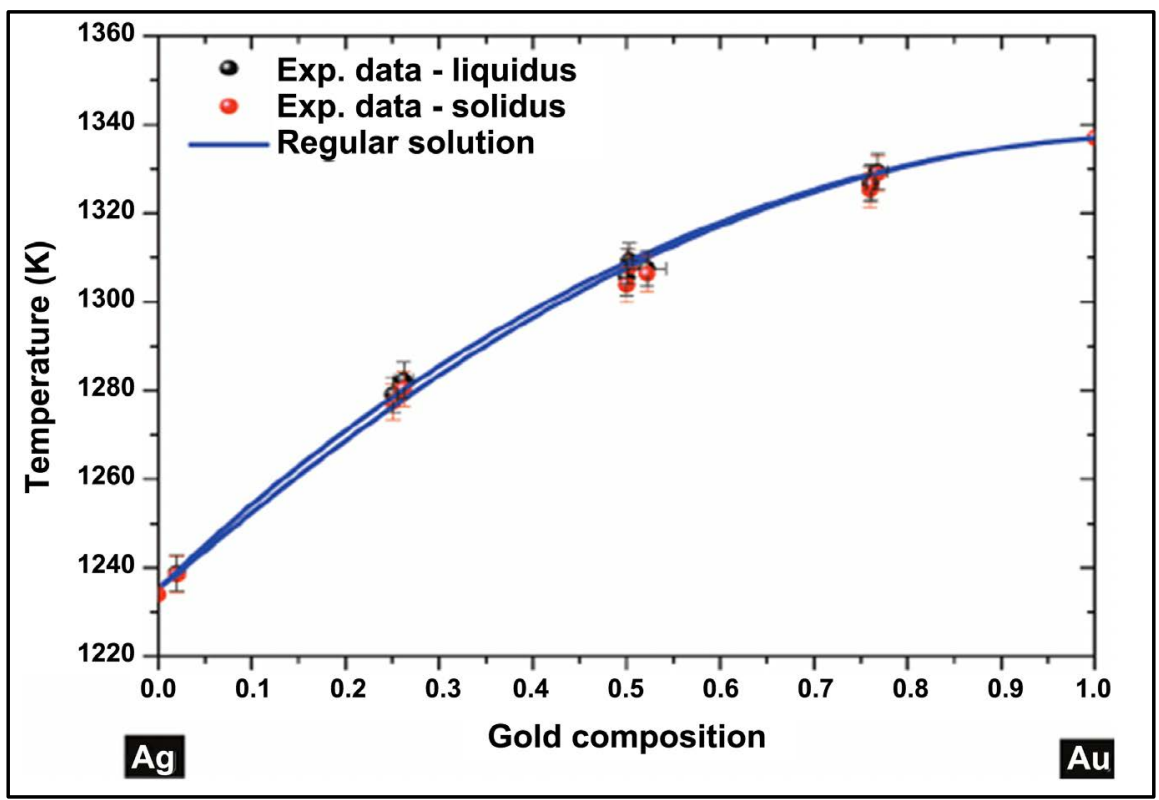

Figure 1. Bulk phase diagram of silver-gold alloy [5]. 
atmospheric oxygen. The resulting molten mass is allowed to cool at room temperature. Alloys of Ag-Ni, Ag-Co, and Cd-Co have large differences in the melting temperatures of the constituent metals. It is pertinent to mention that the elements have the $\mathrm{mp}$ of $\mathrm{Ni}$ is $1453^{\circ} \mathrm{C}$ and on the other hand, $\mathrm{mp}$ of $\mathrm{Ag}$ is $961.78^{\circ} \mathrm{C}$. Similarly, $\mathrm{mp}$ of $\mathrm{Co}$ is $1495^{\circ} \mathrm{C}, \mathrm{mp}$ of $\mathrm{Cd}$ is $321.07^{\circ} \mathrm{C}$, and they cannot be alloyed together in a liquid state. So, their alloys may be easily obtained by electrodeposition [1] [3] [6] rather than usual metallurgical (melting) processes [6]. In electrodeposition process, synchronous deposition of the component metals takes place from the electrolytic solutions, which contain their salts by passing direct electricity [1].

Alloy can also be prepared from simultaneous reduction method. Aluminium bronze is prepared by reduction method, where alumina is reduced in the presence of copper in an electric furnace [1].

Ball Milling is a mechanical process for the formation of alloys or nanocomposites [7] [8]. It is a solid-state powdered metallurgical process, in which kinetic energy is applied to the milled material by the moving balls to break the chemical bonding between them and as a result fresh surfaces are produced [9]. Thus, the powdered metallurgical process allows the preparation of alloys and composites that cannot be synthesized via conventional melting routes [10]. Besides, it has been reported that the impact of a high-energy ball milling process sometimes can create a localized high temperature above $1000^{\circ} \mathrm{C}$ [9] [11] and/or high pressure up to several GPa [9] [12]. Under this drastic ball milling condition, the process has been used as a mechanochemical synthesis for the fabrication of unique nanostructures with new chemical properties. The main objective of milling is the mechanical reduction of the particle size out of a solid sample by grinding with one or more inert balls rotating around a horizontal axis. One can use this solid-state powder processing route to synthesize $\mathrm{PbTe}$ alloy from $\mathrm{PbO}$ and $\mathrm{Te}$ [9] [13]. Other than these, ball milling has also been used recently to fabricate a nanostructured material that has unique properties. Ball milling can be used as a powerful green method to synthesize nitrogen-doped carbon nanoparticles (NDCPs), which can be used as an electrochemical catalyst for oxygen reduction reactions (ORRs) [9]. Ball-milled carbon nanomaterials are a novel class of materials that have been widely used in various energy and environmental applications [14]. Nanocrystalline high entropy alloys (HEAs) can be made easily by high-energy ball milling [15], discovered about 150 years ago. Thus, ball milling has come up to the recently developed nanostage alloying [9]. It may be said that the drastic impact of mechanical strength of the balls creates homogenization of metals. So, under mechanical wear and tear strain, the evolved heat often melts the smaller metal particles. There bulk metals disintegrate into metal nanoparticles and in situ alloying of metal under ball milling takes place. On the other hand, the as-prepared metal nanoparticles are employed as such for metal alloying. Therefore, alloying of metals under ball milling and also with the ex si$t u$ prepared metal nanoparticles for alloy formation become complementary to each other. In addition, alternative approaches, i.e., photochemical and laser ir- 
radiation methods have also been adopted for alloying [16] [17] [18]. Alloy formation and nanoparticle chemistry in the present day context would go hand in hand to obtain newer alloys.

\section{Importance of Nanoparticles for Alloying}

Molten metals are mixed in anticipation of homogenizing the molten metallic components to produce alloy. This has become a normal practice from older days. The idea and choice of integrating metals came from comparative accounts of $\mathrm{mp}$ of the participating metals for strengthening as the prepared metallic counterpart. It is already mentioned that comparing the $\mathrm{mp}$ and boiling points (bp) of metals, we understand that if the bp of solute metal is lower than the mp of solvent metal, solute metal volatilizes and the alloy is not obtained. This is the case of copper $\left(\mathrm{mp}\right.$ is $1085^{\circ} \mathrm{C}$ and $\mathrm{bp}$ is $\left.2562^{\circ} \mathrm{C}\right)$ and that of $\mathrm{Zn}\left(\mathrm{mp}\right.$ is $419.5^{\circ} \mathrm{C}$ and $\mathrm{bp}$ is $907^{\circ} \mathrm{C}$ ). Therefore, to obtain brass, $\mathrm{Zn}$ is dissolved into molten $\mathrm{Cu}$ for alloying. In the case of steelmaking, only $\mathrm{Fe}$ and $\mathrm{C}$ are used, $\mathrm{C}$ is an interstitial impurity $(<1 \%)$. Unlike brass, usual metallurgical processes are adapted to formulate other alloy systems such as alnico, stainless steel, etc. However, there a little difference in their $\mathrm{mp}$, and the solute counterpart has a higher bp than the solute metal component. One important aspect that is eutectic composition (special phase-dependent reaction) of the mixture is considered. Thus, we know that only $3 \%$ of $\mathrm{Ag}$ can hardly be dissolved in solvent $\mathrm{Sn}$. Lowering of $\mathrm{mp}$ of metals in the nano regime becomes an advantage for alloy making. In this feature article liquid phase integration and phase transformation of elements are captured which would go a long way for alloying that too in suitable inert solvent systems like high boiling silicone oil as described later.

In general, metal nanoparticles have attracted much consideration due to their extraordinary properties as nanoparticle has a larger surface-to-volume ratio (larger surface area), which provides them better reactivity from the evolved physical and chemical properties. Due to the decrease in size, it possesses newer thermal as well as quantum confinement effect [19] [20]. Quantum effect becomes much more important and advantageous in miniaturization of objects and characteristics, leading to novel optical, electrical, and magnetic behaviors. It is noteworthy that, decreasing particle size leads to increasing surface chemical potential ( $\mu s)$ and higher surface chemical potential means higher surface energy. Thus, nanoparticles can be beneficially exploited for alloying and very true for catalysis [21]. In addition to these, when the size of the metal sinks to the nanometer range, its $\mathrm{mp}$ decreases drastically. This becomes convincing from the mp of bulk Au and that is $1064^{\circ} \mathrm{C}$ or $1336 \mathrm{~K}$. When the particle size decreases from 100 to $10 \mathrm{~nm}$, melting temperature drops down to $100^{\circ} \mathrm{C}$ [22]. Because of the plethora of novel properties the term nanotechnology has become the subject of discussion of today.

There are several industrial methods to prepare an alloy. Alloy can be prepared by taking bulk metal or by taking metal in their nanostages. To make it 
cost-effective, metal in the nanostage is preferred over bulk metal for alloying from the surface energy consideration. When the $\mathrm{mp}$ of the metal decreases, we can easily fuse them and use the molten mass for alloying. This is well known but leads to a number of important discoveries. One interesting factor of the nanoparticle is that they have excellent phase miscibility that means the metals that are not easily miscible at their bulk stage can form alloy at their nanostage [23]. From Hume-Rothery rules, theoretical information for alloying is obtained, which becomes necessary and inevitable for alloying [24] [25] [26] [27] [28]. William Hume-Rothery suggested some rules to predict whether the two metals or one metal and one nonmetal can form a solid solution. Once they form solid solutions then the type of solid solution is also determined by these rules. $\mathrm{He}$ suggested that there can be two types of solid solution: Substitutional solid solution and Interstitial solid solution [29] [30]. For each of them there are different sets of rules. In substitutional solid solution, solute atoms occupy the regular lattice site of the solvent. To form substitutional solid solution two elements must have a similar crystal structure, electronegativities, valency and the difference between the atomic radii of solute and solvent atoms must not exceed $15 \%$. This implies for $\mathrm{Cu}-\mathrm{Ni}, \mathrm{Au}-\mathrm{Ag}$, system etc. While in interstitial solid solution, solute atoms occupy the interstitial position. Hence, a strain is generated, which affects solubility. When the radii of the solute atoms are much bigger than the radii of the interstitial sites, then there is a displacement of surrounding atoms, caused by the misfit of solute atoms. Hence, strain arises in the matrix. Therefore, this system governs other sets of rules i.e. radius of the solute atoms should have less than $59 \%$ of the radius of the solvent atoms and solute and solvent should have similar electronegativities. Fe-C system in steel is an example of interstitial solid solution.

An elegant example from the above systems is Au-Ag alloy. It is an ideal bimetallic alloy, known from ancient times because of its isomorphic nature. The alloy of the Au-Ag system follows every point of Hume-Rothery rules except their electronegativities (electronegativity value of $\mathrm{Au}$ is 2.54 and that is for $\mathrm{Ag}$ is 1.93 in Pauling scale) even then they attain isomorphic nature. The participating elements $\mathrm{Au}$ and $\mathrm{Ag}$ have a similar atomic radius (atomic radius of both $\mathrm{Au}$ and $\mathrm{Ag}$ is $134 \mathrm{pm})$, crystal structure ( $\mathrm{Ag}=\mathrm{FCC}, \mathrm{Au}=\mathrm{FCC})$ [5] and lattice spacing $(\mathrm{Ag}=4.079 \AA, \mathrm{Au}=4.065 \AA$ ), so they dissolve in all proportions. The alloy which forms the isomorphous structure, bound to follow the law of isomorphism. German chemist Eilhard Mitscherlich has proposed this simple law. According to this law, the substances with similar chemical formulae exhibit similar chemical properties and crystalline forms. Thus, their crystals grow one over the other in a suitable environment. So monotonic growth of the crystal is seen out of the same metal and compound.

As we know, several factors affect the crystal structure of alloys, and it depends on the atomic size, crystal structure, and relative concentration of the participating elements. Nevertheless, when a continuous substitutional solid solution is studied, where randomly distributed atoms or ions substitute each other; 
it became a common practice to consider their lattice parameters for alloying. In 1921, Vegard proposed a law to explain alloy formation considering the variations in lattice parameters of solute in the solvent. He observed that there is a linear relationship exists between the crystal lattice parameter of the substitutional solid solution and the concentrations of the added constituent elements, at a constant temperature. This approximate empirical rule has become known as Vegard's law [31]. This law is valid, when the atomic radii or lattice parameter of added pure components differ only by less than $5 \%$. Again, this law has its validity only for ionic salts and compounds [29]. When there is a disparity of lattice parameter of pure components then Vegard's law is not obeyed [32]. It is not a generalized rule this is an approximation proved by Jacob et al. [31]. However, $\mathrm{Ag}-\mathrm{Au}$ is a unique system, where Vegard's lawfully holds good for all possible $\mathrm{Au}$ and $\mathrm{Ag}$ concentrations. This may be due to the isomorphic nature of $\mathrm{Au}$ and Ag. Previous reports show that Au-Ag nanoalloy is tremendously important in diverse fields like medicine, catalysis, plasmonic, and so on [33] [34] [35] [36] [37]. Like Ag-Au system, another system that follows the law of isomorphism is $\mathrm{Cu}-\mathrm{Ni}$ alloy [38].

An extended illustration but deviation from solid solution is composite formation. There is a huge difference between an alloy and a composite. One can identify them from their phase diagram. An alloy should have at least one metal is mandatory in its composition while composites do not have any metal in its composition. The physical and chemical properties of the constituent of an alloy are different. It is worth mentioning that in an alloy, the chemical properties of the individual constituents are retained and the physical properties lie in between the constituent. Altogether, an alloy stands for a new material with new properties than that of the participating elements. Whereas composites are made from components that have very different chemical and physical properties with different configurations to achieve the necessary combinations of properties such as stiffness, density, rigidity, hardness, thermal and electrical feasibility. They have very different characteristics than their key components. One can separate the individual components of an alloy by physical means, whereas in a composite, chemical reactions must be performed to obtain the original components. Components of alloy cannot be distinguished because solute dissolves in solvents to form a solid solution. Whereas components of composites can be easily identified because there has to be a base or matrix material such as polymer, metal, or ceramics. The second component that is integrated one such as fiber, nanotube, spherical particle, etc. that remains undissolved [39]. An alloy can be a homogeneous or heterogeneous mixture but a composite is always heterogeneous (two different types of phase reinforcing phase and matrix phase or base material bonded together.) and anisotropic in nature. Because their properties depend on the material phase as well as on the direction [40]. Due to the heterogeneous nature, it inherits toughness. One elegant example is cement and concrete. Classification of composites is done by the types of materials used for a matrix such as a polymer matrix composites (PMCs), metal matrix composites 
(MMCs), ceramic matrix composites (CMCs) and carbon matrix composites (CAMCs) [40]. Most alloys can conduct electricity whereas composites do not conduct electricity except polymeric composites such as polyaniline (PANi). In this feature article, we have tried to explore the wide possibilities of implementation of the versatility of the growth mechanisms of alloy formation. Our main intension is to find out the way by which one can link alloying out of the existing ideas for alloy formation in a suitable platform and then crystal growth becomes conceivable especially in the nanoregime.

\section{Growth Mechanisms for Alloy Formation}

The natural abundance of minerals of different metals with overlapping properties; the amalgamation of metals and subsequent transmetalation reaction; size and shape; different surface energy of crystals of metal provide thermodynamics of metal mixing. Again, lowering of $\mathrm{mp}$ of a pure solid substance even with admixed impurity provides concrete evidence towards alloying with a second metal. All this information provoked the scientists and technologists to successively but deliberately lower the mp of metals and then melting different metals together with a different perspective (size factor, crystal structure, affinity-based integration etc.). Thus, the growth of the crystals is explained but with a post facto manner. Mechanism of alloy formation and alloy growth i.e., homogenization of different metals have been substantiated in the following paragraphs, considering the existing growth mechanisms of different crystallites particle evolution has been emphasized here taking redox reactions from solution phase. It is possible from a suitable reduction reaction of a solution of the precursor compound. In the following paragraphs, important mechanisms of the growth of alloy particles with schematic presentations have been described to advocate alloy formation. Previous reports on digestive ripening for a straight forward alloy formation provide clues for a better understanding of the mechanism of alloy formation through digestive ripening [41]. Again, bimetallic Ag-Au nanoparticles with alloyed as well as core-shell structure formation were observed by introducing preformed AuNPs and AgNps in aqueous solution at $75^{\circ} \mathrm{C}$. Interestingly both digestive ripening and Ostwald ripening mechanisms were amenable for the formation of different morphologies, which were corroborated from transmission electron microscopy (TEM) and UV-Vis spectroscopy [42]. Jiang et al., [43] have addressed the formation of ultrathin AgPt alloyed nanowires which becomes an example of oriented attachment process.

\subsection{Oriented Attachment}

In 1998, Penn et al. proposed an important crystal growth mechanism called "Oriented Attachment (OA)", which is also been referred to as oriented aggregation and epitaxial assembly [44] [45] [46] [47]. The alloy formation mechanism can be explained from the underlying OA process. In the OA process, two adjacent nanocrystals undergo self-integration, resulting in crystal growth by sharing 
a common crystallographic orientation [48] [49] [50] [51] [52]. This crucial manifestation is conceived from Hume-Rothery rules that have now become a major research focus in the field of nanoscience and materials science [53] and extensive efforts have been carried out over the past few decades to systematically investigate the growth mechanism and the statistical kinetic models [48] [54] [55]. In this particle mediated crystal growth mechanism, nanocrystals first suffer collision and form loosely bound aggregates, composed of randomly oriented nanocrystals, followed by rearrangement with some preferential crystallographic orientation, leading to irreversible attachments [48] [56] [57]. Preferential plane is a natural choice by the participating crystals. As a result, one can get different morphology such as wires, rods, and branched secondary crystals as the planes may lie in different directions. After the OA process, in many cases, the original microstructural characteristics of the primary units can be retained, and the interfacial defects can be preserved [48]. Reduction of the overall surface energy is the driving force for the OA mechanism [48] [58] [59]. Many efforts have been directed to identify the growth kinetics of nanoparticle in the OA mechanism, but till now people failed to demonstrate the detailed theory behind the OA process [60]. The same explanation holds good for alloying of two particles resulting in variable morphologies.

Alloying and crystal growth is now explained from the below kinetic model Figure 2 through some preferential crystallographic orientation and irreversible rearrangement. During alloying, two interacting particles must have a similar crystal structure as described in the above section.

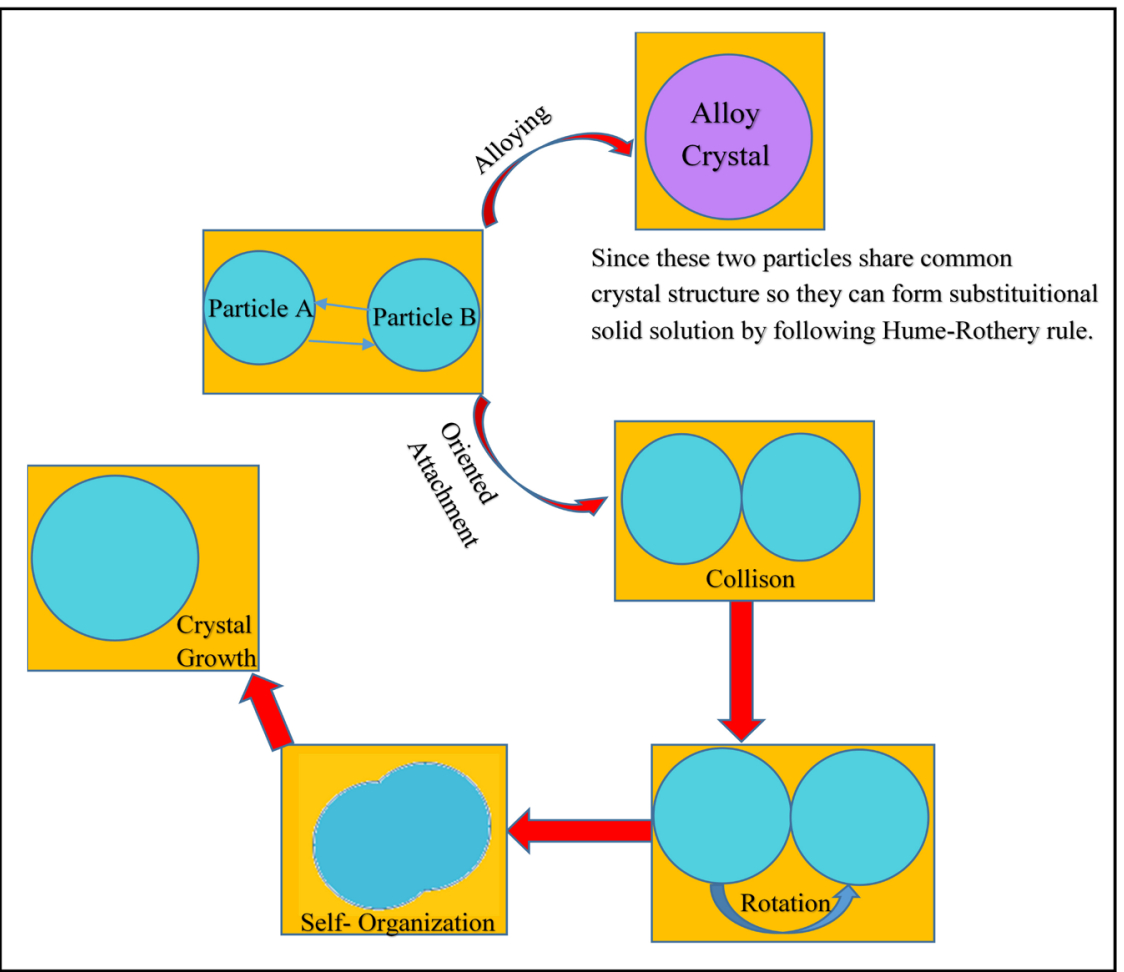

Figure 2. Schematic representation of alloying out of oriented attachment. 


\subsection{Ostwald Ripening}

Ostwald ripening (OR) process is associated with the crystal growth mechanism [61]. It occurs via dissolution of solute particles of smaller crystals dimension and redeposition onto the surface of larger crystals [62] [63] [64] [65]. In 1900, Wilhelm Ostwald systematically investigated the influence of the size of the crystals on their solubility [66]. The driving force for the OR process is the concentration gradient of the solute ions. Since the concentration of the solute ion of the smaller crystal is higher than the concentration of the solute ion of larger crystal, that drives the diffusion of the solute ion from the smaller crystal to larger one [67] [68] [69] [70]. OR is prevalent in oil-in-water emulsions [71] [72] [73] [74]. These phenomena influence the stability of emulsion and eventually lead to phase separation. Therefore, we can define the OR process as a diffusion-controlled growth mechanism. Kinetics of the OR process relies on a decrease in the surface free energy [52]. Thus, smaller particles decrease in size until they disappear and larger particles grow even larger. This shrinking and growing of particles will result in a larger mean diameter of a particle size distribution [75]. The growth of an alloy can easily be looked into the OR in terms of solute-solvent interaction or impurity doping in larger crystallites. Thus, alloying may be envisaged in terms of differences in the radii of the interacting particles. Here, comes the Hume-Rothery rules for the formation of interstitial solid solution i.e. nothing but alloying. The rule describes the comparative account of the radii of the interacting particles i.e. radius of the solute particle (may be dopant/impurity as in case of semiconductor crystal growth) should have less than $59 \%$ of the radius of the solvent molecule, is presented below in Figure 3.

\subsection{Digestive Ripening}

It is very difficult to prescribe a method from which particles of equal sizes are evolved from a solution. However, particle evolution becomes possible from a suitable reduction reaction of a solution of the precursor compound. Therefore, researchers try to divulge processes that give rise to a particle of comparable sizes i.e., as obtained particles would retain a tight size distribution pattern. A novel way to replicate tight size distribution is digestive ripening (DR). This process is inverse of Ostwald ripening and is called digestive ripening (DR) [76] [77]. DR is an effective way to demonstrate the formation of unique monodisperse nanoparticle from polydisperse colonies in the presence of digestive ripening agent [78]-[86]. Klabunde and Sorensen first proposed this process for evolution of monodispersed Au nanocrystals from solution phase [87]. DR significantly reduced the average particle size and polydiversity [88] [89]. To control the nanoparticle size, one can use organic molecules such as thiols, phosphines, carboxylic acid, etc. as capping agents [86] [87] [88] [89] [90], which is chosen for the synthesis of metal nanoparticles mainly from the "Hard Soft Acid-Base (HSAB) theory". In most of the synthesis, the capping agent is present in the reduction 


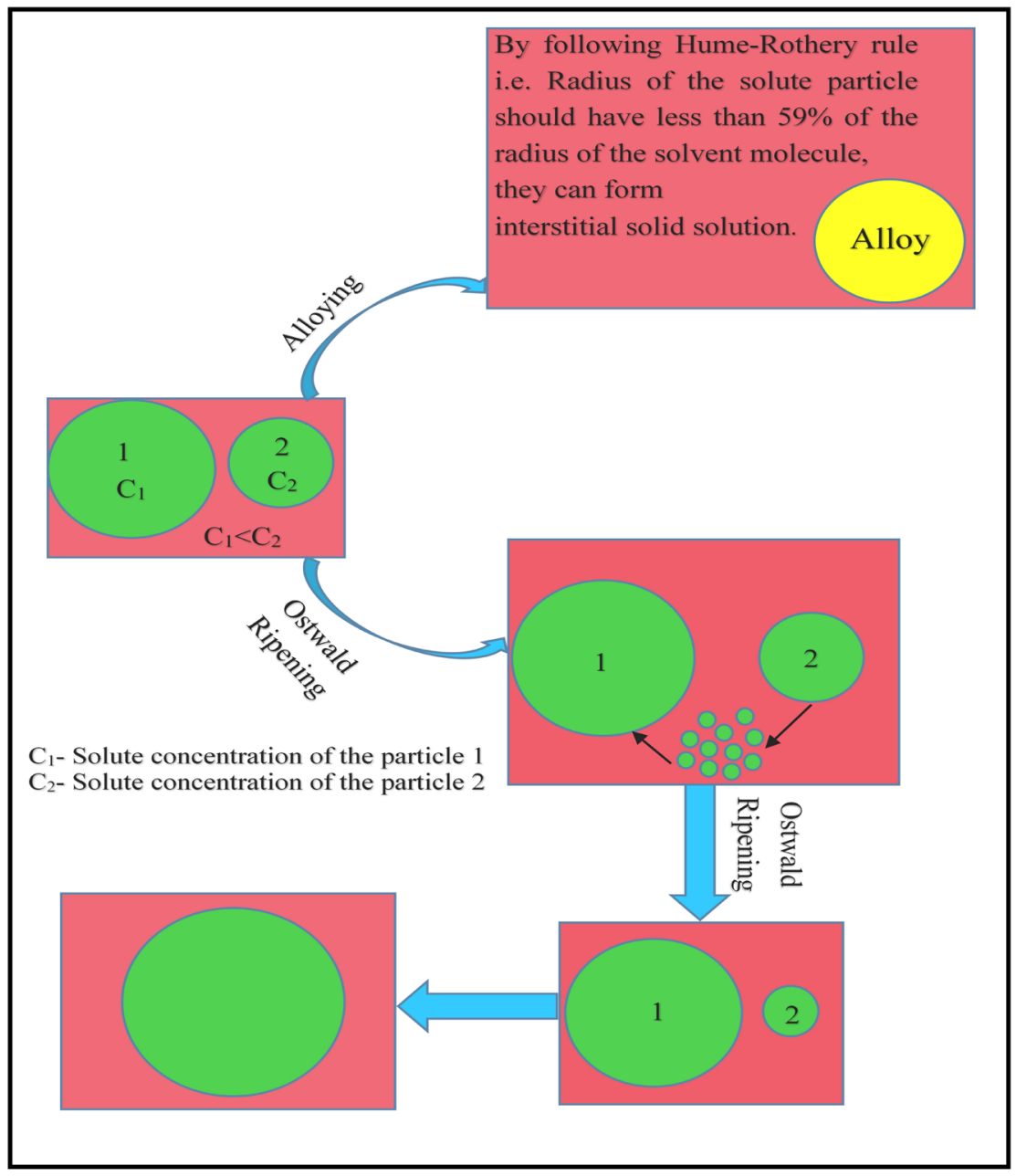

Figure 3. Schematic representation of alloying out of Ostwald ripening.

step, which serves as a protective agent. In the DR process, the capping agent is added in the post-synthesis step for the evaluation and stabilization of metal nanoparticles. Therefore, the DR process has drawn the attention of the researchers by its convenience and efficient method for the preparation of the narrow size distribution of particles [65] [91]. Particles of various sizes can be taken to a particle of equal sizes by the DR process. That means the larger particles will reduce to an average size and the smaller particles will build up to an average size distribution with capping agent [81]. DR process is a very convenient one for synthesizing metal alloy with outstanding but tunable optical properties for plasmonic particles [81]. It has been shown that the refluxing of copper nanoparticles (CuNPs) [79] and silver nanoparticles (AgNPs) [76] [92] with gold nanoparticles (AuNPs) [76] [89] [90] [91] [92] [93] in the presence of digestive ripening agents, results in the formation of $\mathrm{Cu}-\mathrm{Au}$ or $\mathrm{Cu}-\mathrm{Ag}$ alloy nanoparticle [81]. The mechanism behind this interesting alloy formation is the mixing of different metals resulting in the formation of preferential smaller bimetallic alloys [81] [94]. However, in the case of DR, the digestive ripening agent is an essential and obligatory component to stabilize them as obtained particles. 
This DR agent inhibits the collision of the particles bringing steric hindrance. However, in the case of alloying, the digestive ripening agent is redundant. In the absence of this digestive ripening agent, the formation of an alloy can be accounted for by Hume-Rothery rules of substitutional solid solution i.e. the difference of atomic radius of solute and solvent atoms must not exceed 15\%, which is presented in Figure 4. An elegant proposition of DR for alloy formation can be the removal of the digestive ripening agent after the evolution of particles of comparable sizes. Then the as obtained particles would easily coalesce in the absence of steric hindrance, to form an alloy as the interacting particles already describe the similar crystal structure with high surface energy.

Surface energy is the predominant factor here because surface energy controls the crystal structure. Au-Cu alloy nanoparticle has shown excellent application in catalysis, photonics and biomedical research [23] [95] [96] [97]. AuNPs and CuNPs can form their alloy by following three conditions of Hume-Rothery rules i.e. they both share common crystal structure (FCC), they both have similar atomic radii and both have same valency (+1) [23] [95].

Both $\mathrm{Au}$ and $\mathrm{Cu}$ have outstanding plasmonic and catalytic properties. AuNPs can be used for catalysis, drug delivery, photothermal therapy, and pollution control [23] [98] [99]. Similarly, CuNPs can be used as heterogeneous catalysts for many chemical reactions such as reduction of $\mathrm{CO}_{2}$, oxidation of $\mathrm{CO}$, propene, benzyl alcohol [23] [100] [101] [102]. When these two components combine to form an alloy that offers not only sufficient stability and optical properties but also high catalytic activity, owing to the synergistic effect between the right selection of two components [95]. Similarly, $\mathrm{Ag}-\mathrm{Cu}$ alloy nanoparticles were extensively used for its antibacterial and antiseptic applications in the field of medicine and drug delivery [103] [104].

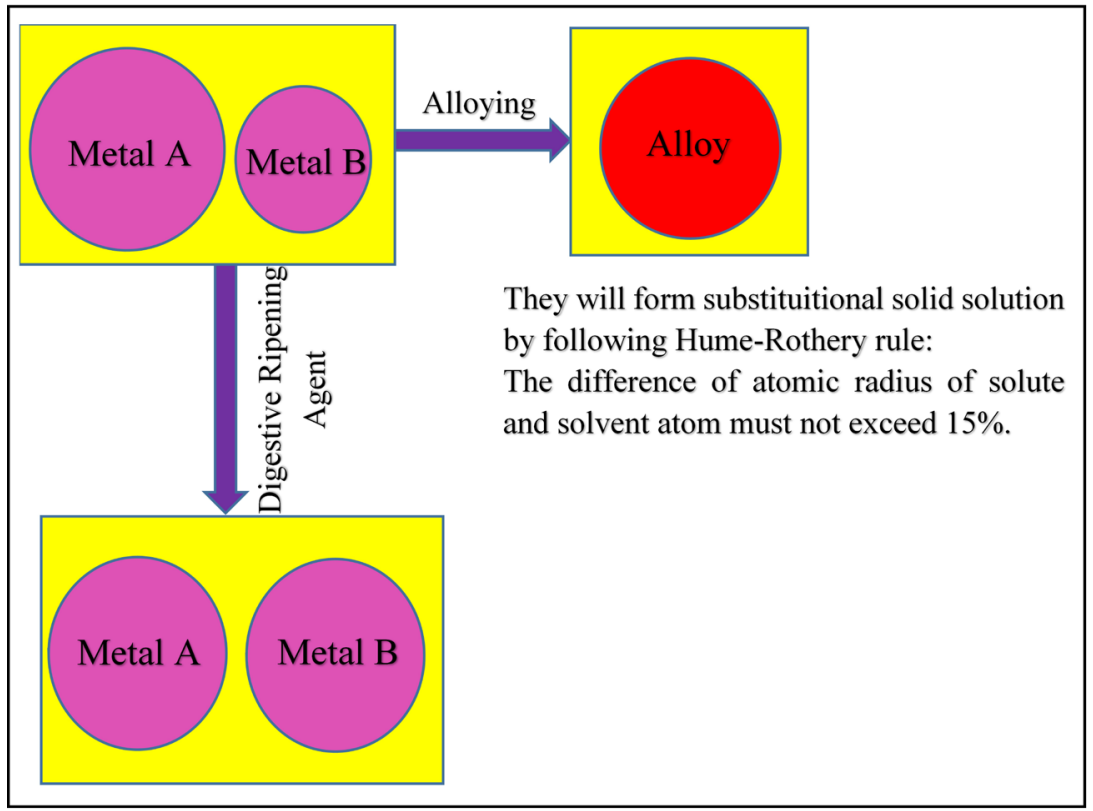

Figure 4. Schematic representation of alloying out of digestive ripening. 


\subsection{Galvanic Replacement Reaction}

Galvanic replacement reaction (GRR) is a redox reaction, in which one metal gets oxidized by ions of another metal having higher reduction potential. Normally, the replacement reaction is in the form of $\mathrm{nM}+\mathrm{mM}_{\text {noble }}^{\mathrm{n}+} \rightarrow \mathrm{nM}^{\mathrm{m}+}+$ $\mathrm{mM}_{\text {noble, }}$ where $\mathrm{M}$ may be $\mathrm{Cu}, \mathrm{Fe}, \mathrm{Ni}, \mathrm{Al}$, etc. and $\mathrm{M}_{\text {noble }}$ may be $\mathrm{Ag}, \mathrm{Au}, \mathrm{Pt}, \mathrm{Pd}$, etc. i.e., having higher reduction potential [105]. GRR provides a simple but versatile way of converting less noble metallic solid nanoparticles into structurally more complex sometimes hollow nanostructures composed of more noble metals [106] [107] [108]. This method has recently found applications for producing unique hollow AuNps by using metalloid As(0) nanoparticles as a template [109] [110]. Which is investigated by TEM imaging. In this case, the reduction of $\mathrm{HAuCl}_{4}$ was carried out by $\mathrm{As}(0)$ in an aqueous phase $(\mathrm{pH}=5.5)$ with the simultaneous oxidation of $\mathrm{As}(0)$ to arsenate $\left(\mathrm{AsO}_{4}^{-}\right)$. The red-colored sol authenticates the formation of $\mathrm{Au}(0)$ which shows $\lambda_{\max }$ at $540 \mathrm{~nm}$ in the absorption spectrum. Oxidation of metalloid arsenic (As) nanoparticles by $\mathrm{Au}$ (III) ions have been described for futuristic plasmonic applications [109]. The reduction potential values of metals are also dependent on the environmental factor [111]. Thus, one can easily manipulate GRR just changes the solvent system judiciously. This method is an indirect replication of the electrodeposition of alloy formation. One important but pertinent information has been included in Table 1.

In recent years, bimetallic nanoparticles fascinated scientists because of their superior optical [112] [113], catalytic [112] [114] and magnetic properties [112]. Bimetallic nanoparticles can be prepared by two different methods from metal salt: co-reduction and successive reduction methods [112]. Co-reduction is a simple method of preparing bimetallic nanoparticles [115]. In this method bimetallic nanoparticles can be achieved by simultaneous reduction of two metal precursors in the presence of a suitable reducing agent from one pot. Whereas successive reduction is carried out and that leads to the evolution of the core-shell structure of bimetallic nanoparticles [112] [116] [117]. It has already come into account and interesting to note that the deposition of less noble metal

Table 1. Standard reduction potential values $\left(\mathrm{E}^{0} \mathrm{~V}(\mathrm{SHE})\right.$ ) of $\mathrm{Cu}, \mathrm{Ag}$ and $\mathrm{Au}$ system in presence of different ligand/nucleophile [111].

\begin{tabular}{cccc}
\hline & \multicolumn{3}{c}{ Redox couple } \\
\hline Ligand/Nucleophile & $\mathrm{Cu}^{+} / \mathrm{Cu}^{0}$ & $\mathrm{Ag}^{+} / \mathrm{Ag}^{0}$ & $\mathrm{Au}^{+3} / \mathrm{Au}^{0}$ \\
\hline $\mathrm{H}_{2} \mathrm{O}$ & +0.521 & +0.799 & +1.500 \\
$\mathrm{Cl}^{-}$ & +0.137 & +0.222 & +1.000 \\
$\mathrm{Br}^{-}$ & +0.033 & +0.090 & +0.870 \\
$\mathrm{SCN}^{-}$ & -0.270 & - & +0.660 \\
$\mathrm{I}^{-}$ & -0.185 & -0.150 & +0.500 \\
$\mathrm{CN}^{-}$ & -0.430 & -0.310 & -0.600 \\
\hline
\end{tabular}


"shell" on the preformed nanoparticles of more noble metal "core" seems to be very effective by clean UV activation [116]. Bimetallic nanoparticles composed of $\mathrm{Au}$ and $\mathrm{Ag}$ have drawn considerable interest to the scientists in the field of nanotechnology due to their intense absorption band in the visible region known as surface plasmon absorption as mentioned earlier. Manipulation of this methodology allows fine-tuning of optical properties with a greater versatility [112] [118] [119] [120]. One can easily form normal core-shell morphology of $\mathrm{Au}-\mathrm{Ag}$, i.e. $\mathrm{Au}_{\text {core }}-\mathrm{Ag}_{\text {shell }}$. Also, different capping agents have been used to stabilize the resulting particles [112]. Keeping this idea in mind, Pande et al. [112] have judiciously introduced unmodified beta-cyclodextrin $(\beta-C D)$ in aqueous solution, which has a double role to play. Beta-CD, a cyclic molecule, but like normal sugar, becomes a relatively stronger reducing agent in alkaline medium (at higher $\mathrm{pH}$ condition). In alkaline condition, it acts as a stabilizing agent [112]. Then both normal core-shell structures $A u_{\text {core }}-A_{\text {gshell }}$ as well as inverted core-shell structure $\mathrm{Ag}_{\text {core }}-\mathrm{Au}_{\text {shell }}$ were synthesized by using $\beta$-CD just by neat manipulation. Formation of $\mathrm{Au}_{\text {core }}-\mathrm{Ag}_{\text {shell }}$ is favorable because the reduction potential of $\mathrm{Au}(\mathrm{III}) / \mathrm{Au}(0)$ is higher than $\mathrm{Ag}(\mathrm{I}) / \mathrm{Ag}(0)$ system [112]. It is worth mentioning that reduction potential of $\mathrm{Ag}$ is $\mathrm{E}_{\mathrm{Ag}(\mathrm{I}) / \mathrm{Ag}(0)}^{0}=0.799 \mathrm{~V}$ versus SHE and $\mathrm{Au}$ is $\mathrm{E}_{\mathrm{Au}(\mathrm{III}) / \mathrm{Au}(0)}^{0}=1.52 \mathrm{~V}$ versus SHE. So, $\mathrm{Au}(0)$, evolved at first, acts as an autocatalyst for $\operatorname{Ag}(\mathrm{I})$ reduction in the $2^{\text {nd }}$ step in the solution. The reaction involved is:

$$
\mathrm{Au}_{\text {core }}+\mathrm{Ag}(\mathrm{I}) \stackrel{\beta-\mathrm{CD}(\mathrm{pH} \sim 10-12)}{\longrightarrow} \mathrm{Au}_{\text {core }}-\mathrm{Ag}_{\text {shell }}
$$

However, the synthesis of an inverted core-shell morphology is a little strange and unique without using any extra reducing agent and from the same pot. It is interesting to observe that if simple GRR proceeds with preformed AgNPs and $\mathrm{Au}$ (III) ion in solution i.e., with $\mathrm{AuCl}_{4(\mathrm{aq})}^{-}$then AuNPs are evolved with a hollow core. In this case out of GRR, AgNPs would be oxidized by $\mathrm{Au}(\mathrm{III})$ and eventually $\mathrm{AuCl}_{4(\text { aq) }}^{-}$is reduced to AuNPs. Therefore, AgNPs would serve as sacrificial templates in the presence of $\mathrm{AuCl}_{4(\mathrm{aq})}^{-}$solution [121]. GRR reaction takes place according to this equation:

$$
3 \mathrm{Ag}_{(\mathrm{s})}+\mathrm{AuCl}_{4_{(\mathrm{aq})}^{-}}^{-} \rightarrow \mathrm{Au}_{(\mathrm{s})}+3 \mathrm{Ag}_{(\mathrm{aq})}^{+}+3 \mathrm{Cl}^{-}
$$

In this case driving force is the difference in the reduction potential between the sacrificial templates and the metal ions in the solutions. According to the above reaction, sacrificial templates undergo oxidation and dissolution simultaneously with the reduction of metal ion followed by deposition over the template surface [121] [122]. Due to the oxidation of $\mathrm{Ag}(0)$ to $\mathrm{Ag}(\mathrm{I})$, GRR favors hollow AuNPs evolution. Formation of AgNPs and hollow-core AuNPs was investigated by several instruments such as scanning electron microscope (SEM), electron dispersive spectroscopy (EDS), and UV-Vis spectroscopy. SEM images of AgNPs and Ag-Au bimetallic nanoparticles revealed the hollow structure of AuNPs. Variation in optical properties for these nanoparticles relative to the AgNPs is 
monitored by recording UV-Vis spectra. AgNPs showed a surface plasmon resonance (SPR) peak at $412 \mathrm{~nm}$, which was due to spherical AgNPs ( 40 nm) and this SPR peak was shifted towards longer wavelength (redshift) and broadened up to $799 \mathrm{~nm}$ due to increase in the Au content in the nanoparticles and formation of Ag-Au hollow structure takes place by GRR [121].

However, if one uses $\beta$-CD-like reducing agents, it becomes kinetically capable of reducing $\mathrm{Au}(\mathrm{III})$ ions in the presence of preformed $\operatorname{Ag}(0)$ and leads to the formation of inverted core-shell architecture $\mathrm{Ag}_{\text {core }}-\mathrm{Au}_{\text {shell }}$ with its excess concentrations [112]. The reaction involved in the inverted core-shell architecture is:

$$
\mathrm{Ag}_{\text {core }}+\mathrm{Au}(\mathrm{III}) \stackrel{\beta-\mathrm{CD}(\mathrm{pH} 10-12)}{\longrightarrow} \mathrm{Ag}_{\text {core }}-\mathrm{Au}_{\text {shell }}
$$

Here, normal oxidation of $\operatorname{Ag}(0)$ is inhibited because of the increase in the oxidation resistance of $\operatorname{Ag}(0)$. Besides, self-organization and hydrophobic interaction of $\beta$-CD with $\mathrm{Ag}(0)$ make $\mathrm{Ag}$ nobler than $\mathrm{Au}$ and lead to the formation of $\mathrm{Ag}_{\text {core }}-\mathrm{Au}_{\text {shell. }}$. Here, the $\mathrm{Au}(\mathrm{III})$ reduction rate is possibly higher than the GRR rate [112]. Confirmation of the formation of normal and inverted core-shell structure is carried out by using several instruments like TEM, EDS, high-resolution TEM (HRTEM), X-ray photoelectron spectroscopy (XPS). From the TEM images, the size of the monometallic $\mathrm{Au}(0), \mathrm{Ag}(0)$, bimetallic $\mathrm{Au}_{\text {core }}-\mathrm{Ag}_{\text {shell }}$ and $\mathrm{Ag}$ core- $-\mathrm{Au}_{\text {shell }}$ can be observed.

The formation of normal and inverted core-shell structure in the presence of $\beta$-CD is confirmed in Figure 5. HRTEM images of the as-prepared samples were carried out. From the HRTEM images, it was confirmed that there is a less dense interior core of silver (lighter than gold) surrounded by a thicker shell of gold (heavier than silver) was present.

Finally, it was reported that unmodified $\beta$-CD supports the kinetic evolution of the desired shell on the preformed seed particles, leaving aside the usual redox reaction. The whole process was illustrated in Figure 6. This manipulation can easily engender alloying in a suitable platform where thermodynamic as well as kinetic aspects are evoked judiciously in the solution phase.

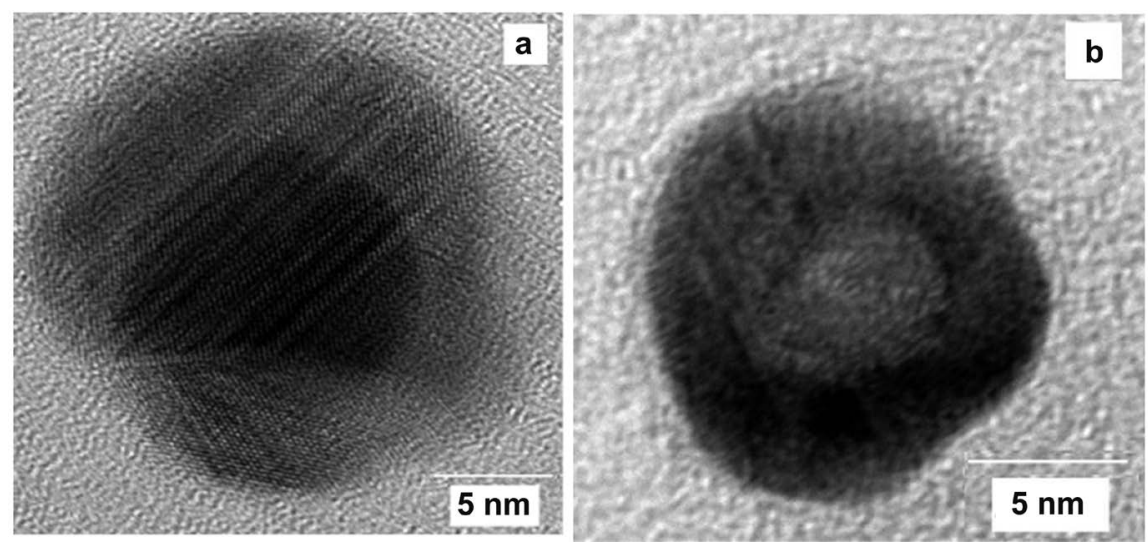

Figure 5. HRTEM images of (a) $A u_{\text {core }}-A_{\text {shell }}$ and (b) $A g_{\text {core- }}-A u_{\text {shell }}$ bimetallic nanoparticles [112]. 


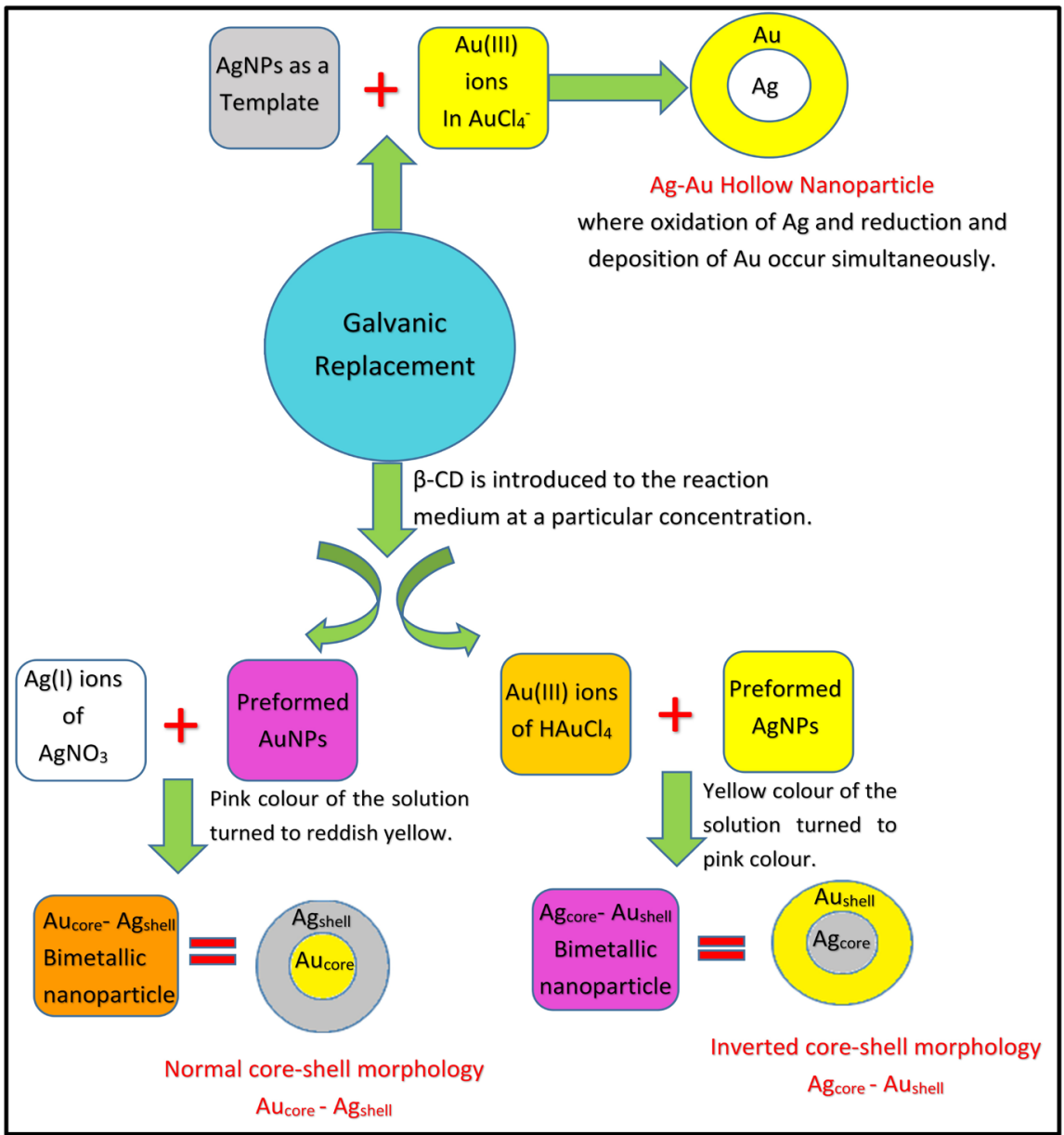

Figure 6. Schematic representation of galvanic replacement reaction.

The GRR has a far-reaching consequence of oxidation and redeposition of metal from a selected solution-phase process. This is a new but neat manipulation for the formation of mono-, bi-, and multimetallic nanoparticles with tuned properties for multifarious applications including plasmonics [123]. In a nutshell, the facile reduction of $\mathrm{Au}(\mathrm{III})$ is possible in the presence of a preformed $\operatorname{Ag}(0)$ particle or vice versa. Again, silver ions (with a lower reduction potential value than gold (III)) and gold ions can be reduced simultaneously to evolve $\mathrm{Au} / \mathrm{Ag}$ alloy from one pot [124]. Once a trace of $\mathrm{Au}(0)$ is produced in the first step in solution and that catalyzes (even trace of $\mathrm{Au}(0)$ in solution) the reduction of $\mathrm{Ag}(\mathrm{I})$ ions. So, $\mathrm{Au}(0)$ acts as an autocatalyst as indicated above that promotes $\mathrm{Ag}(\mathrm{I})$ reduction and eventually $\mathrm{Au} / \mathrm{Ag}$ alloy is obtained.

Again, GRR is a facile procedure to synthesize $\mathrm{Co}-\mathrm{Cu}$ nanoparticles with narrow size and composition distributions [125]. It is also used for the inner matrix synthesis of AgNPs, AuNPs, and bimetallic AgAu nanoparticles for bactericidal and electrocatalytically active nanocomposites [126]. In GRR, if alloy nanoparticles are used as a template, where the reactivities of the metal in the alloy are different from those of the metals in their pure phase then this difference can potentially lower the GRR rates, allow the diffusion of atoms at the boundary 
between different metals (Kirkendall effect), as discussed in the following paragraph to play a more significant role in determining the hollow structure formation [127] [128] [129] [130].

\subsection{Kirkendall Effect}

Kirkendall Effect is a well-known phenomenon resulting from the difference in the diffusion rates of the metal ion [131] [132]. There are three types of diffusion mechanisms leading to Kirkendall Effect: 1) Direct Exchange mechanism, 2) Ring Diffusion mechanism and 3) Vacancy Diffusion mechanism [133]. However, in direct exchange mechanism, atoms can exchange their position directly, movement of each atom across the interface encourages another atom to move across but in the other direction, and distortions take place. Since, lattice strain is associated with this mechanism, so more energy should be supplied to carry out the reaction mechanism (large change in free energy). Hence, this is energetically forbidden. We can overcome the situation with the ring diffusion mechanism but we cannot neglect the distortion. As in the ring diffusion mechanism, distortion can be reduced but as many atoms are involved in this process, so this mechanism also leads to lattice strain. Therefore, these above two mechanisms are redundant. Now considering the third mechanism, vacancy diffusion mechanism. To understand the vacancy diffusion mechanism we consider the case of $\mathrm{Cu}$-Brass $(\mathrm{Cu}+\mathrm{Zn})$ system. In the $\mathrm{Cu}$-brass system, $\mathrm{Cu}$ and brass are separated by an interface. Since, the diffusion coefficient of zinc $(\mathrm{Zn})$ in brass is higher than $\mathrm{Cu}$, so $\mathrm{Zn}$ atom will cross the interface at a higher rate than the $\mathrm{Cu}$ atom [134]. As diffusion progresses, more number of $\mathrm{Zn}$ atoms leave the brass and enter into the $\mathrm{Cu}$ region. Thus, the size of the brass region decreases (vacancies will be created), and more vacancies will be consumed by the $\mathrm{Zn}$ atoms in the $\mathrm{Cu}$ region. In the whole process, there is always a net flow of atom in one side and equal and opposite flow of vacancy in another side. The apparent shift of the interface is explained by the vacancy diffusion mechanism. Now it is well understood that the Kirkendall effect is a vacancy diffusion-driven process. Hence, in Kirkendall effect, place exchange reaction takes place between a preformed alloy and a metal to form a new alloy system by using the idea of diffusion coefficient, which is also observed in case of GRR [135].

\section{Alloy Formation in High Boiling Liquid}

New and interesting physical and chemical properties emerge out because of alloying. Over the past few decades, nanoparticles have elicited attention due to many innovative applications such as biomedicine, catalysis, solar cell, fuel cell, self-cleaning coating, etc. Again, device making has the propensity to advance and miniaturize daily commodities at large. Since their uniqueness depends on their size and shape, so more emphasis is given to control the size and shape of the nanoparticles. Alloying nanoparticles are of great interest due to their unique functionalities. Several costly metals are having better properties but their cost and high $\mathrm{mp}$ restrict us to alloy them. To address these challenges, we can lower 
down the particle size of metals for alloy formation, which provides another way to amend the properties of the costly metal by exemplary manipulations. Thus, cost-effective as well as the new materials emerge out have better expediency than their parent metal nanoparticle from which they are prepared. This nice tampering with the size of the metal came out as another promising step towards alloying. When their size decreases to the nanometer range, their $\mathrm{mp}$ decrease drastically. In general, nanoparticles are highly reactive and reactivity increases successively with the decrease in size. Now the question arises how we can protect them from atmospheric corrosion. This is because of the progressive shift of Fermi level towards negative reduction potential [136] [137]. Thus, they are oxidized easily in air. They lose their key properties such as optical properties, catalytic properties when they come in contact with oxygen. To overcome these difficulties, a common method of alloying can be made easier by introducing a high boiling liquid. A typical example is silicone oil. Silicone oil can be chosen as a suitable dispersion medium for alloying multimetallic elements. Silicone oil is a high boiling liquid $\left(\mathrm{bp}>250^{\circ} \mathrm{C}\right)$, capable of melting many metallic nanoparticles [138]. Thus, one liquid metal acts as a unique dispersion medium and other add metals become solute. Thus, a dispersion medium silicone oil can be the better choice for alloying elements besides that they have to follow all Hume-Rothery rules. It provides a protective coating to the nanoparticle to resist oxidation, as nanoparticles are highly reactive. Therefore, silicone oil is forwarded to make alloy cost-effective and to make use of precious metal for nano stage alloying. Therefore, keeping this idea in mind Pande et al. [138] have introduced silicone oil in their reaction as a dispersion medium to synthesize nanoparticles as well as their alloy. They have reported a successful gram level synthesis of lead-free solder Sn-Ag alloy nanoparticle by using ethylene glycol-silicone oil mixed solvent system [138]. Participating $\mathrm{Sn}$ and $\mathrm{Ag}$ easily alloyed together because of $\mathrm{mp}$ lowering (lowest $\mathrm{mp}$ of $\mathrm{Ag}$ in nanostage is $112^{\circ} \mathrm{C} \sim 3.5 \mathrm{~nm}, \mathrm{mp}$ of bulk $\mathrm{Sn}$ is $231.9^{\circ} \mathrm{C}$ ) in their nanostages. In this work, Sn-Ag alloy has been synthesized as nanoparticles both externally ( $\mathrm{x}$ situ) as well as in silicone oil (in situ). In generality, the alloy particles are obtained in silicone oil under refluxing conditions $\left(240^{\circ} \mathrm{C}\right)$. Besides, Pande et al. [138] have explained the importance of silicone oil to inhibit the oxidation of nanoparticles and their alloy. Silicone oil offers a protective coating by capturing nanoparticles in a distinct chamber in the chain-like structure in its polymer matrix. The proposed method caters to the increasing interest in the application of nanostage metal alloys as low-temperature lead-free solder [138]. In the past, soft solder i.e., Sn-Pb alloy, a unique material has been discovered for soldering which is having low in cost, low eutectic temperature, and excellent solderability [138]. Nowadays more attention is given to lower the eutectic temperature or melting temperature of an alloy. In the $\mathrm{Sn}-\mathrm{Pb}$ alloy system, $\mathrm{Pb}-61.9 \% \mathrm{Sn}$ composition is important because at this composition system, it shows eutectic behavior [139]. The temperature at this composition is known as "Eutectic Temperature i.e. $183^{\circ} \mathrm{C}$ ". The particular alloy is known as the eutectic alloy, which is presented below in Figure 7. 


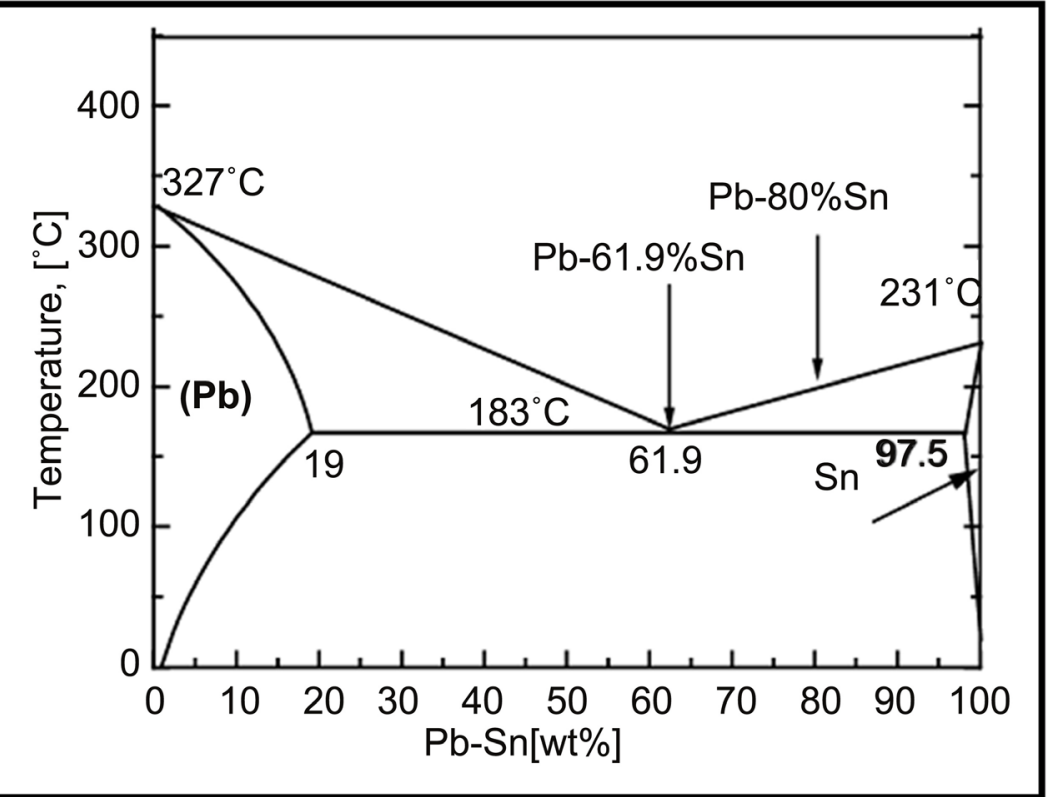

Figure 7. The Phase diagram of the Pb-Sn system [139].

Due to environmental concern, the toxicity of lead cannot be neglected. That is why lead-containing solder is banned all over the globe. Therefore, attention has been directed to discover lead-free solder. However, there is some problem associated with this lead-free solder, which is due to have higher mp than Sn-Pb solder. It put some limitations on their application to temperature-sensitive components. To overcome this situation, Pande et al. [138] provided an idea to attempt nanosized binary lead-free solder such as Sn-Ag nanoalloy at the solder reflow temperature $\left(<260^{\circ} \mathrm{C}\right)$ by introducing the key properties of the nanoparticles. The highest electrical conductivity and lower $\mathrm{mp}$ of $\mathrm{Ag}$ in nanometer-scale encouraged them to use $\mathrm{Ag}$ in place of $\mathrm{Pb}$ [138]. Alloying of Sn-Ag was done at its eutectic composition i.e. Sn/Ag 96.5:3.5 in silicone oil dispersion medium at $240^{\circ} \mathrm{C}$. They have discussed several processes for making Sn-Ag alloy with silicone oil and hydrazine hydrate as a reducing agent and with silicone oil and ethylene glycol as a reducing agent. In both processes, advantages as well as disadvantages, emerge out. In the first process, they have used hydrazine hydrate as a reducing agent and preformed AgNPs were added to the bulk tin powder in presence of silicone oil as a dispersion medium at $240^{\circ} \mathrm{C}$ under $8 \mathrm{~h}$ reflux then also Sn-Ag nanoalloy was formed but the particle size obtained in this process was $\sim 100 \mathrm{~nm}$ Figure $8(\mathrm{a})$. The endothermic peak associated with the $\mathrm{mp}$ of $\mathrm{Sn}-\mathrm{Ag}$ nanoalloy was obtained at $228^{\circ} \mathrm{C}$. However, in the second process, they have used ethylene glycol-silicone oil mixed solvent system for the reduction as well as alloying. Employment of Sn(II) acetate and $\mathrm{Ag}(\mathrm{I})$ acetate in ethylene glycol and silicone oil at $240^{\circ} \mathrm{C}$ under $8 \mathrm{~h}$ reflux, well served the purpose to obtain soldering material. In addition, they have done almost $2 \mathrm{~h}$ sonication. Due to the effect of sonication, the particle obtained in this case was smaller in size $(\sim 30$ nm) Figure 8(b). 


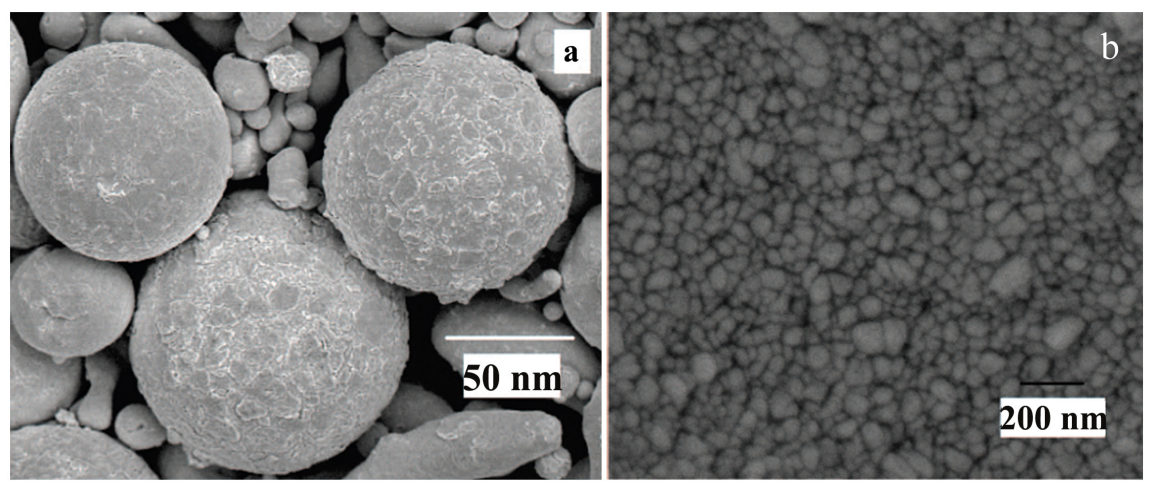

Figure 8. FESEM images of (a) Sn-Ag nanoalloy produced by using silicone oil with hydrazine hydrate and preformed AgNPs at $240^{\circ} \mathrm{C}$ under $8 \mathrm{~h}$ reflux without sonication. (b) Sn-Ag nanoalloy produced by using silicone oil with ethylene glycol and $\mathrm{Ag}(\mathrm{I})$ acetate as precursor instead of their preformed nanoparticles at $240^{\circ} \mathrm{C}$ under $8 \mathrm{~h}$ reflux and $2 \mathrm{~h}$ sonication [138].

Moreover, it is well known that if the particle size will decrease then mp will also decrease. Therefore, in the second process, the endothermic peak associated with the $\mathrm{mp}$ of $\mathrm{Sn}-\mathrm{Ag}$ nanoalloy lowers down to $128^{\circ} \mathrm{C}$. In this case, ethylene glycol serves as both reducing agents as well as capping agent. There are some advantages associated with the first process. Hydrazine hydrate first reduces $\mathrm{Ag}$ to AgNps and makes the environment inert by removing all oxygen from the reaction vessel by evolving nitrogen gas $\left(\mathrm{N}_{2}\right.$ gas). However, the disadvantage of using hydrazine hydrate is also there, it leaves a direction for the formation of metallic boride, which may obstruct the properties of soldering. Besides, they were using preformed AgNPs, which was quite expensive as well as time-consuming. In the second case, ethylene glycol was used instead of hydrazine hydrate with silicone oil. Hydrazine hydrate cannot be used in this case due to the thermodynamic barriers as it cannot reduce $\mathrm{Sn}(\mathrm{II})$ acetate. However, oxidation of $\operatorname{Sn}(0)$ by $\operatorname{Ag}(\mathrm{I})$ is prevented in the silicone oil medium. The advantages in the second process are that introduction of silicone oil along with ethylene glycol makes the reduction potential of $\mathrm{Sn}(\mathrm{II}) / \mathrm{Sn}(0)$ more positive (reduction potential of $\mathrm{Sn}(\mathrm{II}) / \mathrm{Sn}(0)=-0.14 \mathrm{~V}$ ) and silver produced by in situ reaction helps in the catalytic reduction of $\mathrm{Sn}(\mathrm{II})$ to $\mathrm{Sn}(0)$. The reduction of $\mathrm{Sn}$ (II) is possible because of the changed diffusion resistance and charge transfer resistance [112] [138]. There are many advantages associated with silicone oil but on the contrary, silicone oil is difficult to remove from the as-prepared alloy surface because it is a sticky solvent. Therefore, the black colored alloy residue obtained by Pande et al. [138] was washed with petroleum ether (60 - 80) and tetrahydrofuran (THF). So, a new solvent system has been introduced that cleans the Sn-Ag alloy surface easily.

Having inspired by the above-mentioned work, for the first time, Sinha et al. [140] in 2014 have reported the transformation of amorphous selenium (a-Se) micro/nanoballs to trigonal selenium ( $\mathrm{t}-\mathrm{Se}$ ) by different solvents for the possible applications of Se. This method provides a suitable platform to be used as a sol- 
vent (nano Se), a medium for alloying metals. Thus, metal Se nanoalloys can be produced in gram quantity for electronics, plasmonic and biological applications. The importance of silicone oil and the novel application of oriented attachment and Ostwald ripening procedure have been highlighted in this section. A red-colored a-Se nanoballs (a-SNBs) was obtained in silicone oil $\left(\sim 230^{\circ} \mathrm{C}\right)$ dispersion medium under an argon environment. At first, a yellow liquid was obtained, which contains molten Se. When this yellow liquid-cooled to room temperature $\left(\sim 25^{\circ} \mathrm{C}\right)$, red-colored a-Se obtained due to phase transformation. After removing silicone oil from the surface of the as-prepared SNBs, it was kept in different solvents. They observed a thrilling morphological transformation of SNBs in different solvents. They obtained nanoflowers in THF, nanowires in acetone, nanorods in cyclohexanone, etc. For the first time, they apprised the world with such a solvent selective morphology change of Se. This unique method trapped the whole world for preparing a-SNB, t-Se nanoflower, t-Se nanowire, t-Se nanorod without using any costly organoselenium compound or redox chemical reaction with toxic reagents is presented in Figure 9.

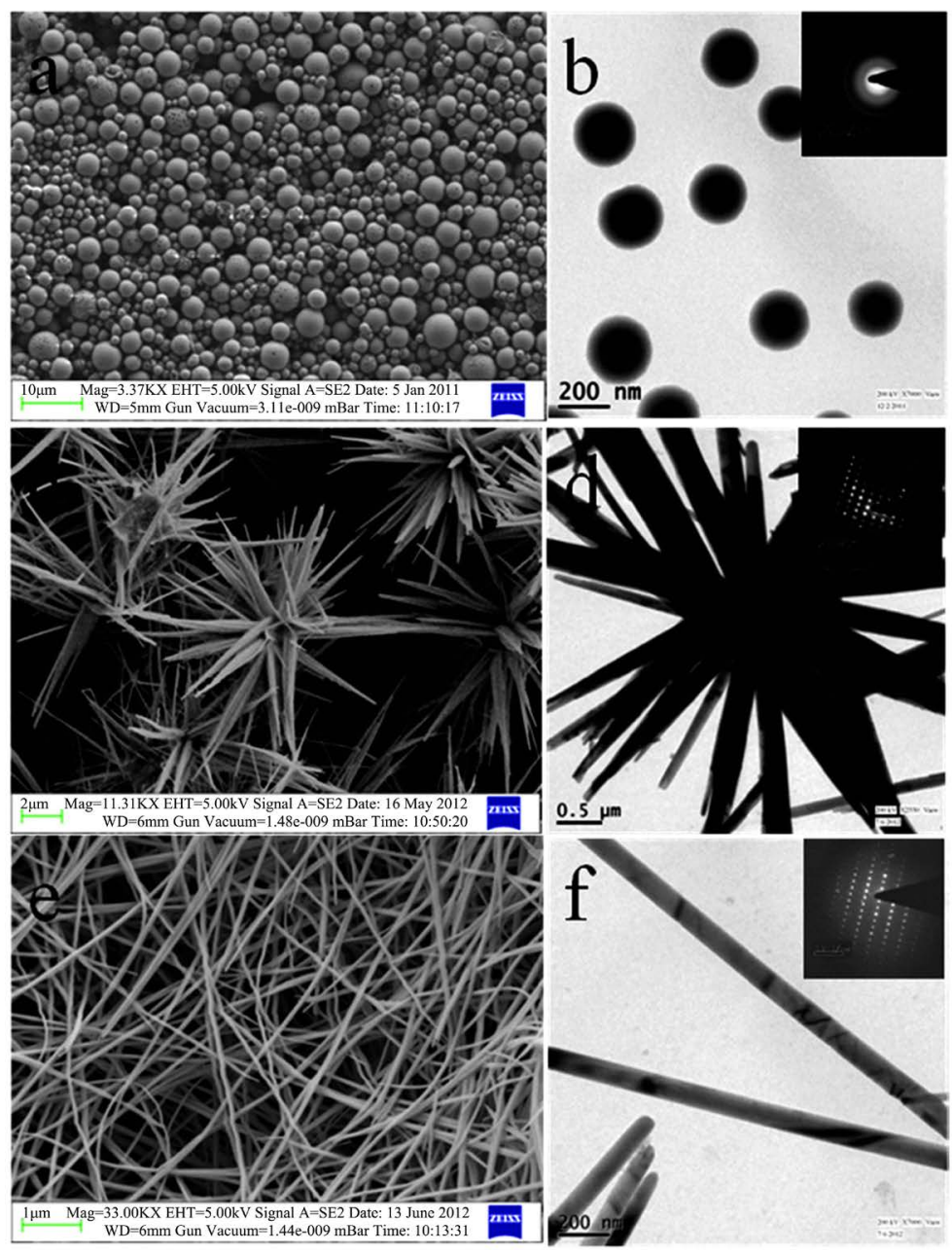

Figure 9. FESEM images of (a) Se nanoballs (SNBs), (c) nanoflowers, (e) nanowires, and TEM images of (b) Se nanoballs (SNBs), (d) nanoflowers and (f) nanowires [140]. 
When SNBs were kept in THF solvent for a week, 1-D Se nanorods that look like flowers, obtained because of oriented attachment and Ostwald ripening. Figure 10 shows ex situ TEM measurements that confirmed the shape transformation of a-Se to t-Se.

It is worth mentioning that amalgamation and subsequent alloying of metals in mercury $(\mathrm{Hg})$ is a suitable option for process development of alloy formation including trans-alloying. There Fe, Pt, W, and Ta have to be excluded for amalgamation with Hg. Varying the morphology of a metal, alloy formation may be thought of at the tips (higher surface energy) position of the parent metal. Finally, the natural abundance of metals in ores and minerals may be given importance in the alloy formation.

\section{Usefulness of Alloys}

The usages of alloys are endless. Due to their versatile applications and properties, innumerable alloys are used in our day-to-day life. It can exhibit qualities that are inaccessible with parent metals [6]. Taking this into account, bronze, the first alloy of $\mathrm{Cu}$ and $\mathrm{Sn}$ saw the light of the day. Alloys are made to enhance the hardness of metals, ductility, Young's modulus, solderability, etc. They also have exceptional electrical and thermal performance, heat resistance sometimes. Alloys are made to lower the $\mathrm{mp}$ because this makes the metals easily fusible [1] and increases the tensile strength of the parent metal. Alloying a metal increases the inertness of the metal, which in turn, increases corrosion resistance. With

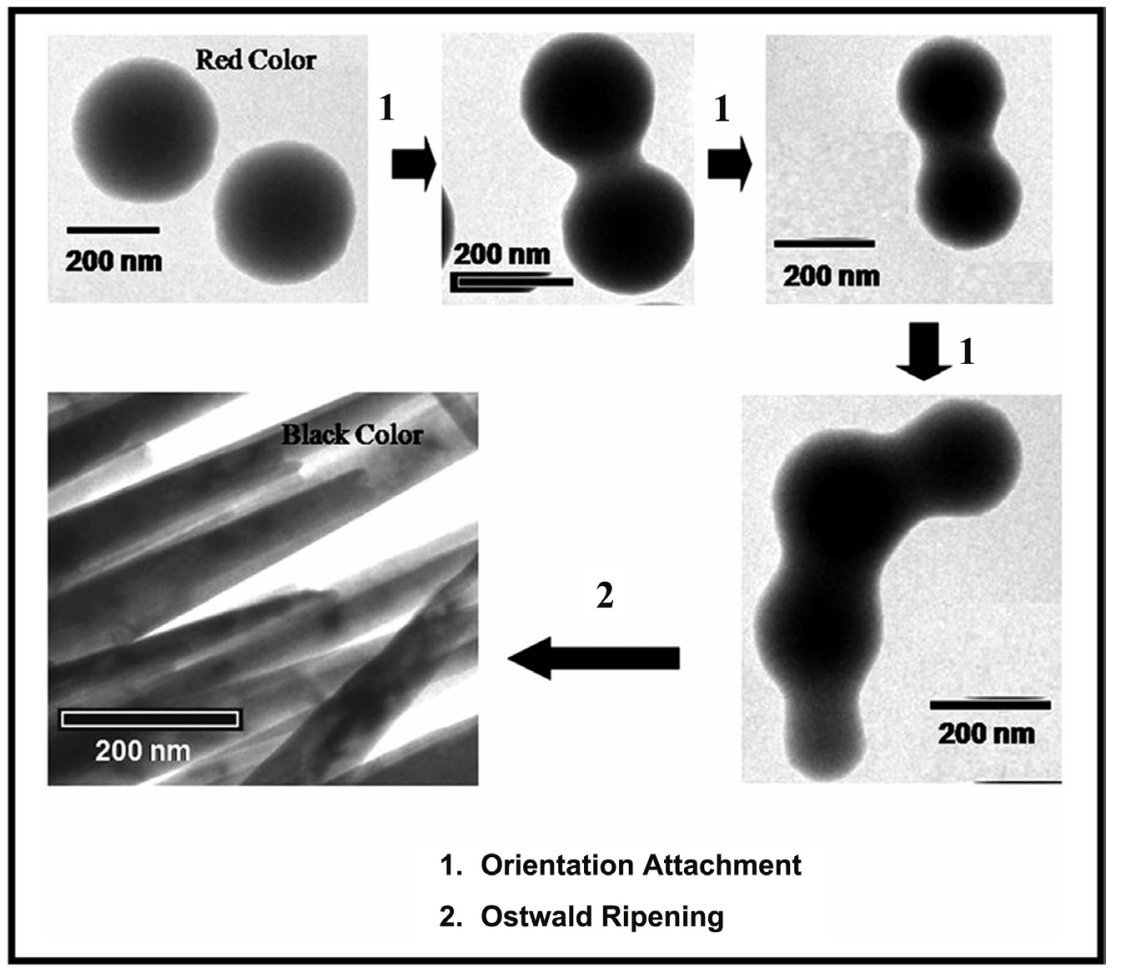

Figure 10. Growth mechanism of Se nanorods from spherical particles via Ostwald ripening (Investigated by TEM analysis) [140]. 
this information, metallurgists tried to produce steel or alloy steel in the $1^{\text {st }}$ century AD in China for the first time. Since, alloy formation is an entropy-driven process. Nowadays HEAs have drawn the attention of the researcher due to their distinct design concepts. They have unique compositions, microstructures, and adjustable properties [38]. They are being used for a wide range of structures such as transportation as well as energy sectors and functional applications. They have excellent mechanical as well as corrosion resistance properties [15] [25]. Strengthening of solid solution is more effective in HEAs than in conventional alloys [38]. Because HEAs have 5 or more than 5 principal elements, whereas conventional alloys have only one principal element [38]. Each principal elements in HEAs should have a concentration between 5 and 35 atomic percent (at.\%) [38]. The concentration of minor elements other than principal elements should have below 5 at.\%. If we compare the entropy of mixing of HEAs with conventional alloy then one can find that entropy of mixing of HEAs is much higher than the conventional alloy. As we have already mentioned a decrease in free energy leads to alloy formation in the previous section. It is noteworthy that, if mixing entropy becomes higher, then significantly free energy should be lower to facilitate the formation of a solid solution with a decreasing number of phases at a higher temperature. Due to the presence of multiple principal elements, it form single-phase or multiphase composites. Large mixing entropy is the dominating factor for the HEAs. In this case, the classical Hume-Rothery rule is not applicable that governs the formation of a solid solution [141]. If the multimetallic alloy is made in a nano-crystalline state, they possess high strength coupled with high ductility.

There are several types of alloys. Depending on their physical and chemical properties, they are used in a different field. There are different types of alloys such as:

1) Corrosion resisting alloys are very precious metal alloys. These alloys can resist corrosion by developing a thin protective film such as oxide on the metal surface. To mention a few, stainless steel, Al-based alloy, Ni-based alloy, bronzes come under this.

2) A eutectic alloy is a mixture of components whose $\mathrm{mp}$ is lower than that of its components. For example, $\mathrm{Sn}-\mathrm{Pb}$ alloy, $\mathrm{Cu}-\mathrm{Ag}$ alloy, etc.

3) Fusible alloy is a metal alloy, which can be easily fused or melted at low temperatures. This type of alloy is used in soldering, safety devices such as fire sprinklers etc. This alloy consists of metals such as $\mathrm{Bi}, \mathrm{Sn}, \mathrm{Pb}, \mathrm{Cd}$, In, Sb because they have lower $\mathrm{mp}$ (below $232^{\circ} \mathrm{C}$ ).

4) A magnetic alloy contains at least one of the three magnetic elements i.e. $\mathrm{Fe}, \mathrm{Ni}$, or Co. For example, alnico (Fe, $\mathrm{Ni}, \mathrm{Co}$, and $\mathrm{Al}$ ), steel (Fe, C), permalloy $(\mathrm{Fe}, \mathrm{Ni})$, etc.

5) Shape-Memory alloy undergoes temperature-driven phase transformation [142]. They can be deformed when cooled but return to its pre-deformed shape when heated. The most important shape-memory alloy is a nickel-titanium (Ni-Ti) alloy [143]. It exists in two phases: austenite and martensite. Upon cool- 
ing, the transition from the austenite phase to the martensite phase started. During deformation, a twinned martensite structure formed then application of load, leads to deformed martensite. Again, by increasing the temperature, deformed martensite transforms into austenite is presented in Figure 11. Shape-memory alloys are appropriate for aircraft, spacecraft, automotive as well as for biomedical applications [142] [143].

\section{Instrumental Methods to Identify an Alloy Formation}

It is said that the present-day discovery of new materials relies only on the results obtained from the analytical instruments. These major instruments (X-ray diffractometer, XRD, TEM and SEM) are almost essential to study newer materials. They are briefly mentioned here for their usefulness. These three instruments are mostly responsible for breakthrough discoveries of nanoparticles and new alloy formation. Analysis of alloys in particular is done by XRD studies. It is a very useful instrumental method to identify an alloy and alloy composition. It describes the phase purity of an alloy, the crystal structure, and the lattice parameter of the phases [144]. It has already been spelled out that this physical method can identify single or multi-phase conjectures of new materials selectively. Even one can easily infer the difference between an isomorphous and eutectic system to reveal miscible components.

Then discovery and advancement of microscopy have enriched solid-state physics especially nanoscience and nanotechnology. Two major instruments, TEM and SEM machines respectively from 1931 and 1937 have become essential for solid-state science. TEM operates on the same optical principles as the normal optical microscope but imparts atomic resolution for materials. More importantly

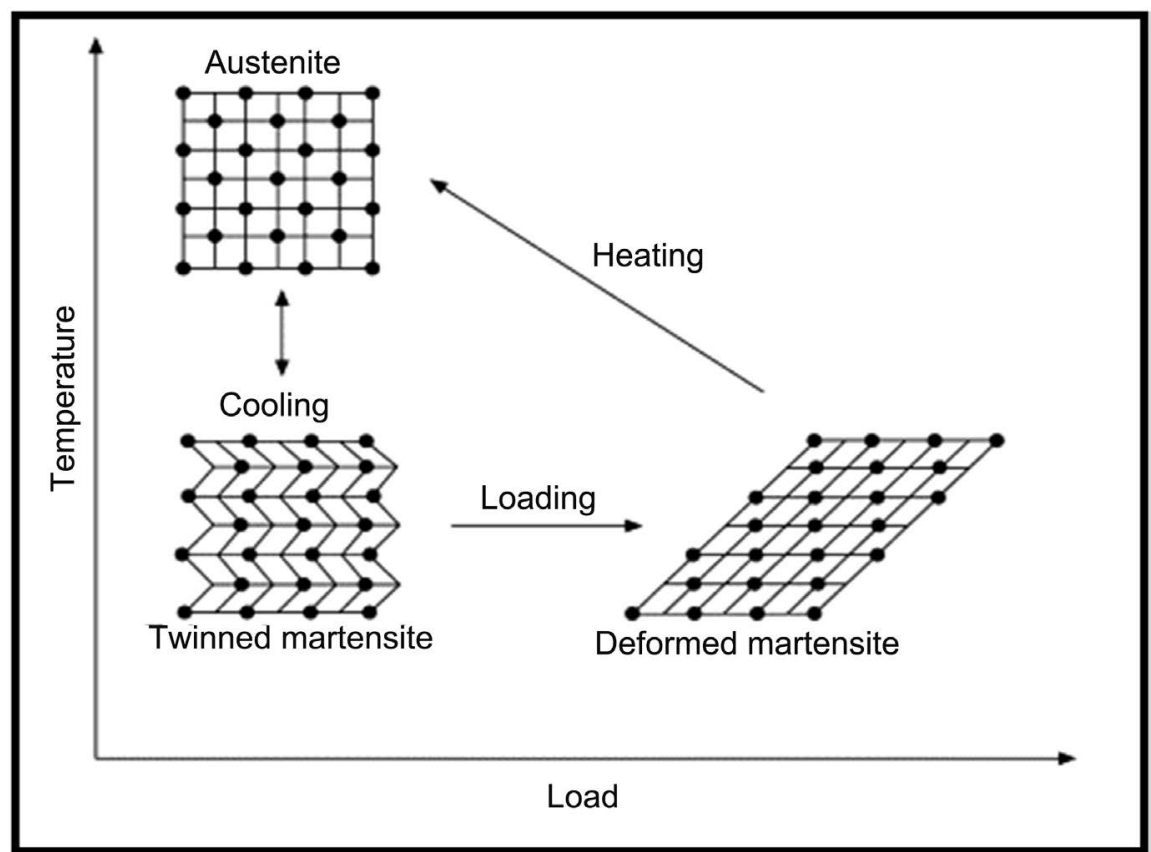

Figure 11. Effect of load and temperature in Ni-Ti alloy [143]. 
instead of the light source in an optical microscope, the TEM machine uses an electron beam (i.e., particle beam) that is transmitted through the sample. This is indeed necessary for imaging nanometer-size particles; they are much smaller than that of the wavelength of visible light. Therefore, electron (particle with smaller de Broglie wavelength) beams can image the nanometer-sized particles. This is possible because of the closeness in sizes of the interacting wavelengths of the particles i.e. wavelength of electron and wavelength of test particles (wave-particle duality).

SEM is also an electron microscope that produces surface topography and composition of a sample with a focused beam of electrons. It scans the surface with an electron beam and a secondary electron detector detects the secondary electrons from the excited atoms (reflected electrons) of the material surface.

\section{Conclusions}

To obtain a solid solution requires knowledge of thermodynamics and skills of manipulation. Innumerable applications with solid solutions are widespread in every walk of life and technology including industries. Thus, it becomes very important and a huge chapter. Elaboration of the growth mechanism of alloy and depiction of plasmonic alloy particles with $\mathrm{Ag}$ and $\mathrm{Au}$, in particular, requires an understanding of crystal structures that helps to produce newer coating material, lubricants, paints, durable materials, cutting tools, lighter aircraft, etc. Despite a lot of ongoing research on alloy formation and crystal growth mechanism, there are still many challenges to produce high-temperature lubricating alloys, bone-implanting alloys, corrosion-resistant alloys etc. for all industries and in the domestic fronts. Here, the liquid phase integration is enriched with crystal growth mechanisms and thermodynamics for alloy formation. Metal nanoparticles under dispersion in a high boiling liquid for obtaining alloys even in the laboratory scale have been discussed for the $1^{\text {st }}$ time and understanding of solute-solvent interaction is given as a post facto manner. Thus, Se nanoparticles of variable morphologies are evolved. Melting point, size factor, electronegativity, reduction potential, valency, etc. are considered for alloying of metal with metal and metal with a nonmetal. It is emphasized that the crystal structure of the participating constituents plays an important role in alloying. The success of nanostage alloying in high boiling liquid and main characterization techniques have become a wealth of information, which is included here very briefly. This brief survey shows the direction towards novel thoughts, which would help diversified field applications in chemistry, biology, nanoscience, plasmonic device making, and other industries.

In the future, researchers should focus to find/develop high boiling liquid, like silicone oil or polymeric compounds, which would ease the future integration of metals in liquid phase even under applied pressure. In addition to this, different sustainable manufacturing technologies of alloy formation should be developed for the production of affordable, eco-friendly smart alloys to meet the need of 
different industries to combat corrosion, wear \& tear, temperature resistance coating, cutting tools.

\section{Declaration of Interests}

The authors declare that they have no known competing financial interests or personal relationships that could have appeared to influence the work reported in this paper.

\section{Acknowledgements}

D. Roy is thankful to Prof. Tarasankar Pal for helpful discussions and suggestions. We are thankful to all the reviewers for suggestions and constructive comments.

\section{Conflicts of Interest}

The authors declare no conflict of interest.

\section{References}

[1] Raj, G. (2011) Alloys and Intermetallic Compounds. In: Chatwal, M., Ed., Advanced Inorganic Chemistry, Krishna Prakashan Media (P) Ltd., Meerut, Uttar Pradesh, 965-988.

[2] Habashi, F. (2008) Alloys: Preparation, Properties, Applications. Wiley VCH Verlag GmbH Weinheim, Germany.

[3] Erb, U., Palumbo, G. and McCrea, J.L. (2011) The Processing of Bulk Nanocrystalline Metals and Alloys by Electrodeposition. In: Whang, S.H., Ed., Nanostructured Metals and Alloys. Processing, Microstructure, Mechanical Properties and Applications, Woodhead Publishing Limited, Cambridge, UK, 118-151. https://doi.org/10.1533/9780857091123.1.118

[4] Delogu, F. and Mulas, G. (2010) Kinetic Processes and Mechanisms of Mechanical Alloying. In: Sopicka-Lizer, M., Ed., High-Energy Ball Milling. Mechanochemical Processing of Nanopowders, Woodhead Publishing Limited, Cambridge, UK, 92-110. https://doi.org/10.1533/9781845699444.1.92

[5] Guisbiers, G., Mendoza-Cruz, R., Bazán-Díaz, L., Velazquez-Salazar, J.J., Mendoza-Perez, R., Robledo-Torres, J.A., Rodriguez-Lopez, J.-L., Montejano-Carrizales, J. M., Whetten, R.L. and José-Yacamán, M. (2016) Electrum, the Gold-Silver Alloy, from the Bulk Scale to the Nanoscale: Synthesis, Properties, and Segregation Rules. ACS Nano, 10, 188-198. https://doi.org/10.1021/acsnano.5b05755

[6] Jović, V.D., Lačnjevac, U.Č. and Jović, B.M. (2014) Electrodeposition and Characterization of Alloys and Composite Materials. In: Djokić, S.S., Ed., Electrodeposition and Surface Finishing. Fundamentals and Applications, Modern Aspects of Electrochemistry 57, Springer, New York, 1-84. https://doi.org/10.1007/978-1-4939-0289-7 1

[7] Zhao, H., Zeng, H., Wu, Y., Zhang, S., Li, B. and Huang, Y. (2015) Facile Scalable Synthesis and Superior Lithium Storage Performance of Ball-Milled $\mathrm{MoS}_{2}$-Graphite Nanocomposites. Journal of Materials. Chemistry A, 3, 10466-10470. https://doi.org/10.1039/C5TA00472A

[8] Bao, D., Gao, P., Shen, X., Chang, C., Wang, L., Wang, Y., Chen, Y., Zhou, X., Sun, 
S., Li, G. and Yang, P. (2014) Mechanical Ball-Milling Preparation of Fullerene/Cobalt Core/Shell Nanocomposites with High Electrochemical Hydrogen Storage Ability. ACS Applied Material and Interfaces, 6, 2902-2909. https://doi.org/10.1021/am405458u

[9] Xing, T., Sunarso, J., Yang, W., Yin, Y., Glushenkov, A.M., Li, L.H., Howlett, P.C. and Chen, Y. (2013) Ball Milling: A Green Mechanochemical Approach for Synthesis of Nitrogen Doped Carbon Nanoparticles. Nanoscale, 5, 7970-7976. https://doi.org/10.1039/c3nr02328a

[10] Nagesha, K.V., Rajanish, M. and Shivappa, D.A. (2013) A Review on Mechanical Alloy. International Journal of Engineering Research and Applications, 3, 921-924.

[11] James, S.L., Adams, C.J., Bolm, C., Braga, D., Collier, P., Friščić, T., Grepioni, F., Harris, K.D.M., Hyett, G., Jones, W., Krebs, A., Mack, J., Maini, L., Orpen, A.G., Parkin, I.P., Shearouse, W.C., Steed, J.W. and Waddell, D.C. (2012) Mechanochemistry: Opportunities for New and Cleaner Synthesis. Chemical Society Reviews, 41, 413-447. https://doi.org/10.1039/C1CS15171A

[12] Chen, X.H., Yang, H.S., Wu, G.T., Wang, M., Deng, F.M., Zhang, X.B., Peng, J.C. and Li, W.Z. (2000) Generation of Curved or Closed-Shell Carbon Nanostructures by Ball-Milling of Graphite. Journal of Crystal Growth, 218, 57-61.

https://doi.org/10.1016/S0022-0248(00)00486-3

[13] Rojas-Chávez, H., Diáz-de la Torre, S., Jaramillo-Vigueras, D. and Plascencia, G. (2009) $\mathrm{PbTe}$ Mechanosynthesis from $\mathrm{PbO}$ and Te. Journal of Alloys and Compound, 483, 275-278. https://doi.org/10.1016/j.jallcom.2008.07.202

[14] Lyu, H., Gao, B., He, F., Ding, C., Tang, J. and Crittenden, J.C. (2017) Ball-Milled Carbon Nanomaterials for Energy and Environmental Applications. ACS Sustainable Chemistry and Engineering, 5, 9568-9585. https://doi.org/10.1021/acssuschemeng.7b02170

[15] Mary, S.J., Nagalakshmi, R. and Epshiba, R. (2015) High Entropy Alloys Properties and its Applications-An Overview. European Chemical Bulletin, 4, 279-284.

[16] Gurskii, Z. and Krawczyk, J. (2003) The Role of Atomic Static Displacements in Binary-Alloy Formation. Physica B: Condensed Matter, 337, 255-265. https://doi.org/10.1016/S0921-4526(03)00412-5

[17] Yamada, Y., Shikano, S. and Fukuzumi, S. (2015) Ni-Cu Alloy Nanoparticles Loaded on Various Metal Oxides Acting as Efficient Catalysts for Photocatalytic $\mathrm{H}_{2}$ Evolution. RSC Advances, 5, 44912-44919. https://doi.org/10.1039/C5RA04838A

[18] Wang, W., Takata, N., Suzuki, A., Kobashi, M. and Kato, M. (2020) Formation of Multiple Intermetallic Phases in a Hypereutectic Al-Fe Binary Alloy Additively Manufactured by Laser Powder Bed Fusion. Intermetallics, 125, Article ID: 106892. https://doi.org/10.1016/j.intermet.2020.106892

[19] Henglein, A. (1989) Small-Particle Research: Physicochemical Properties of Extremely Small Colloidal Metal and Semiconductor Particles. Chemical Reviews, 89, 1861-1873. https://doi.org/10.1021/cr00098a010

[20] Ercolessi, F., Andreoni, W. and Tosatti, E. (1991) Melting of Small Gold Particles: Mechanism and Size Effects. Physical Review Letters, 66, 911-914.

https://doi.org/10.1103/PhysRevLett.66.911

[21] Sharma, N., Ojha, H., Bharadwaj, A., Pathak, D.P. and Sharma, R.K. (2015) Preparation and Catalytic Applications of Nanomaterials: A Review. RSC Advances, 5, 53381-53403. https://doi.org/10.1039/C5RA06778B

[22] Ichinose, N., Ozaki, Y. and Kashu, S. (1992) Physics of Superfine Particles. In: 
James, M., Ed., Superfine Particle Technology, Springer-Verlag, London, 21-38. https://doi.org/10.1007/978-1-4471-1808-4 2

[23] Thota, S., Wang, Y. and Zhao, J. (2018) Colloidal Au-Cu Alloy Nanoparticles: Synthesis, Optical Properties and Applications. Materials Chemistry Frontiers, 2, 1074-1089. https://doi.org/10.1039/C7QM00538E

[24] Takeuchi, T., Onogi, T., Banno, E. and Mizutani, U. (2001) Direct Evidence of the Hume-Rothery Stabilization Mechanism in Al-Mn-Fe-Si Mackay-Type 1/1-Cubic Approximants. Materials Transactions, 42, 933-938. https://doi.org/10.2320/matertrans.42.933

[25] Troparevsky, M.C., Morris, J.R., Daene, M., Wang, Y., Lupini, A.R. and Stocks, G.M. (2015) Beyond Atomic Sizes and Hume-Rothery Rules: Understanding and Predicting High Entropy Alloys. JOM, 67, 2350-2363.

https://doi.org/10.1007/s11837-015-1594-2

[26] Mizutani, U., Takeuchi, T. and Sato, H. (2004) Interpretation of the Hume-Rothery Rule in Complex Electron Compounds: $\gamma$ Phase $\mathrm{Cu}_{5} \mathrm{Zn}_{8}$ Alloy, FK-Type $\mathrm{Al}_{30} \mathrm{Mg}_{40} \mathrm{Zn}_{30}$ and MI-Type $\mathrm{Al}_{68} \mathrm{Cu}_{7} \mathrm{Ru}_{17} \mathrm{Si}_{8}$ 1/1-1/1-1/1 Approximants. Progress in Materials Science, 49, 227-261. https://doi.org/10.1016/S0079-6425(03)00035-5

[27] Zhang, Y.M., Yang, S. and Evans, J.R.G. (2008) Revisiting Hume-Rothery's Rules with Artificial Neural Networks. Acta Materialia, 56, 1094-1105.

https://doi.org/10.1016/j.actamat.2007.10.059

[28] Wang, Z., Huang, Y., Liu, C.T., Li, J. and Wang, J. (2019) Atomic Packing and Size Effect on the Hume-Rothery Rule. Intermetallics, 109, 139-144.

https://doi.org/10.1016/j.intermet.2019.04.001

[29] Massalski, T.B. (1996) Structure and Stability of Alloys. In: Cahn, R.W. and Haasen, P., Eds., Physical Metallurgy, North-Holland, Amsterdam, The Netherlands, 135-204.

[30] Hume-Rothery, W., Mabbott, G.W. and Channel Evans, K.M. (1934) The Freezing Points, Melting Points, and Solid Solubility Limits of the Alloys of Silver and Copper with the Elements of the B Sub-Groups. Philosophical Transactions of the Royal Society London A, 233, 1-97. https://doi.org/10.1098/rsta.1934.0014

[31] Jacob, K.T., Raj, S. and Rannesh, L. (2007) Vegard's Law: A Fundamental Relation or an Approximation? International Journal of Materials Research, 98, 776-779. https://doi.org/10.3139/146.101545

[32] Petkov, V., Maswadeh, Y., Vargas, J.A., Shan, S., Kareem, H., Wu, Z.-P., Luo, J., Zhong, C.-J., Shastri, S. and Kenesei, P. (2019) Deviations from Vegard's Law and Evolution of the Electrocatalytic Activity and Stability of Pt-Based Nanoalloys Inside Fuel Cells by in Operando X-ray Spectroscopy and Total Scattering. Nanoscale, 11, 5512-5525. https://doi.org/10.1039/C9NR01069F

[33] Betz, G., Braun, P. and Färber, W. (1977) Studies of Surface Composition of Ag-Au, $\mathrm{Au}-\mathrm{Cu}$ and Ag-Cu Alloys after Ion Bombardment by Auger Electron Spectroscopy. Journal of Applied Physics, 48, 1404-1407.

[34] Link, S., Wang, Z.L. and El-Sayed, M.A. (1999) Alloy Formation of Gold-Silver Nanoparticles and the Dependence of the Plasmon Absorption on Their Composition. Journal of Physical Chemistry B, 103, 3529-3533. https://doi.org/10.1021/jp990387w

[35] Liu, S., Chen, G., Prasad, P.N. and Swihart, M.T. (2011) Synthesis of Monodisperse $\mathrm{Au}, \mathrm{Ag}$ and $\mathrm{Au}-\mathrm{Ag}$ Alloy Nanoparticles with Tunable Size and Surface Plasmon Resonance Frequency. Chemistry of Materials, 23, 4098-4101. https://doi.org/10.1021/cm201343k

[36] Shanmugasundaram, T., Radhakrishnan, M., Gopikrishnan, V., Kadirvelu, K. and Balagurunathan, R. (2017) Biocompatible Silver, Gold and Silver/Gold Alloy Nano- 
particles for Enhanced Cancer Therapy: In Vitro and In Vivo Perspectives. Nanoscale, 9, 16773-16790. https://doi.org/10.1039/C7NR04979J

[37] Russo, L., Puntes, V. and Merkoçi, A. (2018) Tunable Electrochemistry of Gold-Silver Nanoshells. Nano Research, 11, 6336-6345.

https://doi.org/10.1007/s12274-018-2157-y

[38] Zhang, Y., Zuo, T.T., Tang, Z., Gao, M.C., Dahmen, K.A., Liaw, P.K. and Lu, Z.P. (2014) Microstructures and Properties of High Entropy Alloys. Progress in Materials Science, 61, 1-93. https://doi.org/10.1016/j.pmatsci.2013.10.001

[39] Chawla, K.K. (2012) Composite Materials: Science and Engineering. Springer-Verlag, New York.

[40] Zweben, C. (2015) Composites Materials. In: Kutz, M., Ed., Mechanical Engineer's Handbook: Materials and Engineering Mechanics, John Wiley \& Sons, Hoboken, NJ, 401-435. https://doi.org/10.1002/9781118985960.meh110

[41] Destro, P., Cantaneo, D.A., Meira, D.M., dos Santos Honório, G., da Costa, L.S., Bueno, J.M.C. and Zanchet, D. (2018) Formation of Bimetallic Copper-Gold Alloy Nanoparticles Probed by In Situ X-Ray Absorption Fine Structure Spectroscopy. European Journal of Inorganic Chemistry, 2018, 3770-3777.

[42] Ji, Y., Yang, S., Guo, S., Song, X., Ding, B. and Yang, Z. (2010) Bimetallic Ag/Au Nanoparticles: A Low Temperature Ripening Strategy in Aqueous Solution. Colloids and Surfaces A: Physicochemical and Engineering Aspects, 372, 204-209. https://doi.org/10.1016/j.colsurfa.2010.10.028

[43] Jiang, X., Fu, G., Wu, X., Liu, Y., Zhang, M., Sun, D., Xu, L. and Tang, Y. (2018) Ultrathin AgPt Alloy Nanowires as a High-Performance Electrocatalyst for Formic Acid Oxidation. Nano Research, 11, 499-510. https://doi.org/10.1007/s12274-017-1658-4

[44] Penn, R.L. and Banfield, J.F. (1998) Imperfect Oriented Attachment: Dislocation Generation in Defect-Free Nanocrystals. Science, 281, 969-971.

[45] Zhang, H., Penn, R.L., Lin, Z. and Cölfen, H. (2014) Nanocrystal Growth via Oriented Attachment. Crystal Engineering Communications, 16, 1407-1408. https://doi.org/10.1039/c4ce90001d

[46] Yong, K.-T., Sahoo, Y., Zeng, H., Swihart, M.T., Minter, J.R. and Prasad, P.N. (2007) Formation of ZnTe Nanowires by Oriented Attachment. Chemistry of Materials, 19, 4108-4110. https://doi.org/10.1021/cm0709774

[47] Balankura, T., Yan, T., Jahanmahin, O., Narukatpichai, J., Ng, A. and Fichthorn, K.A. (2020) Oriented Attachment Mechanism of Triangular Ag Nanoplates: A Molecular Dynamics Study. Nanoscale Advances, 2, 2265-2270. https://doi.org/10.1039/D0NA00124D

[48] Xue, X., Penn, R.L., Leite, E.R., Huanga, F. and Lin, Z. (2014) Crystal Growth by Oriented Attachment: Kinetic Models and Control Factors. Crystal Engineering Communications, 16, 1419-1429. https://doi.org/10.1039/c3ce42129e

[49] Kim, Y.H., Lee, J.H., Shin, D.-W., Park, S.M., Moon, J.S., Nam, J.G. and Yoo, J.-B. (2010) Synthesis of Shape-Controlled $\beta-\operatorname{In}_{2} S_{3}$ Nanotubes through Oriented Attachment of Nanoparticles. Chemical Communications, 46, 2292-2294. https://doi.org/10.1039/b922366e

[50] Mullaugh, K.M. and Luther III, G.W. (2011) Growth Kinetics and Long-Term Stability of CdS Nanoparticles in Aqueous Solution under Ambient Conditions. Journal of Nanoparticle Research, 13, 393-404.

https://doi.org/10.1007/s11051-010-0045-9 
[51] Grillo, F., Zara, D.L., Mulder, P., Kreutzer, M.T. and van Ommen, J.R. (2018) Oriented Attachment and Nanorod Formation in Atomic Layer Deposition of $\mathrm{TiO}_{2}$ on Graphene Nanoplatelets. Journal of Physical Chemistry C, 122, 19981-19991. https://doi.org/10.1021/acs.jpcc.8b05572

[52] Zhang, J., Huang, F. and Lin, Z. (2010) Progress of Nanocrystalline Growth Kinetics Based on Oriented Attachment. Nanoscale, 2, 18-34.

https://doi.org/10.1039/B9NR00047I

[53] Meng, J., Hou, C., Wang, H., Chi, Q., Gao, Y. and Zhu, B. (2019) Oriented Attachment Growth of Monocrystalline Cuprous Oxide Nanowires in Pure Water. Nanoscale Advances, 1, 2174-2179. https://doi.org/10.1039/C8NA00374B

[54] Cho, K.-S., Talapin, D.V., Gaschler, W. and Murray, C.B. (2005) Designing PbSe Nanowires and Nanorings through Oriented Attachment of Nanoparticles. Journal of American Chemical Society, 127, 7140-7147. https://doi.org/10.1021/ja050107s

[55] Zhang, Q., Liu, S.-J. and Yu, S.-H. (2009) Recent Advances in Oriented Attachment Growth and Synthesis of Functional Materials: Concept, Evidence, Mechanism and Future. Journal of Materials Chemistry, 19, 191-207.

https://doi.org/10.1039/B807760F

[56] Lee, E.J.H., Ribeiro, C., Longo, E. and Leite, E.R. (2005) Oriented Attachment: An Effective Mechanism in the Formation of Anisotropic Nanocrystals. Journal of Physical Chemistry B, 109, 20842-20846. https://doi.org/10.1021/jp0532115

[57] Wang, F. and Wang, X. (2014) Mechanisms in the Solution Growth of Free-Standing Two-Dimensional Inorganic Nanomaterials. Nanoscale, 6, 6398-6414. https://doi.org/10.1039/c4nr00973h

[58] Sahoo, R., Roy, A., Dutta, S., Ray, C., Aditya, T., Pal, A. and Pal, T. (2015) Liquor Ammonia Mediated $\mathrm{V}(\mathrm{V})$ Insertion in Thin $\mathrm{Co}_{3} \mathrm{O}_{4}$ Sheets for Improved Pseudocapacitors with High Energy Density and High Specific Capacitance Value. Chemical Communications, 51, 15986-15989. https://doi.org/10.1039/C5CC06005B

[59] Lv, W., He, W., Wang, X., Niu, Y., Cao, H., Dickerson, J.H. and Wang, Z. (2014) Understanding the Oriented-Attachment Growth of Nanocrystals from an Energy Point of View: A Review. Nanoscale, 6, 2531-2547. https://doi.org/10.1039/C3NR04717B

[60] Cao, D., Gong, S., Shu, X., Zhu, D. and Liang, S. (2019) Preparation of ZnO Nanoparticles with High Dispersibility Based on Oriented Attachment (OA) Process. Nanoscale Research Letters, 14, Article No. 210. https://doi.org/10.1186/s11671-019-3038-3

[61] Pradhan, M., Roy, A., Sinha, A. K., Sahoo, R., Deb, D. and Pal, T. (2015) Solid-State Transformation of Single Precursor Vanadium Complex Nanostructures to $\mathrm{V}_{2} \mathrm{O}_{5}$ and $\mathrm{VO}_{2}$ : Catalytic Activity of $\mathrm{V}_{2} \mathrm{O}_{5}$ for Oxidative Coupling of 2-Naphthol. Dalton Transactions, 44, 1889-1899. https://doi.org/10.1039/C4DT02863E

[62] Gentry, S.T., Kendra, S.F. and Bezpalko, M.W. (2011) Ostwald Ripening in Metallic Nanoparticles: Stochastic Kinetics. Journal of Physical Chemistry C, 115, 12736-12741. https://doi.org/10.1021/jp2009786

[63] Voorhees, P.W. (1985) The Theory of Ostwald Ripening. Journal of Statistical Physics, 38, 231-252. https://doi.org/10.1007/BF01017860

[64] Yao, J.H., Elder, K.R., Guo, H. and Grant, M. (1993) Theory and Simulation of Ostwald Ripening. Physical Review B, 47, 14110-14125.

https://doi.org/10.1103/PhysRevB.47.14110

[65] Irzhak, V.I. (2017) Digestive Ripening of Nanoparticle. Russian Journal Physical Chemistry A, 91, 1502-1506. https://doi.org/10.1134/S0036024417080131 
[66] Yec, C.C. and Zeng, H.C. (2014) Synthesis of Complex Nanomaterials via Ostwald Ripening. Journal of Materials Chemistry A, 2, 4843-4851. https://doi.org/10.1039/C3TA14203E

[67] Sugimoto, T. (2001) Recrystallization. In: Sugimoto, T., Monodispersed Particles, Elsevier Science B.V., Amsterdam, The Netherlands, 139-154. https://doi.org/10.1016/B978-044489569-1/50022-1

[68] Hansen, T.W., DeLaRiva, A.T., Challa, S.R. and Datye, A.K. (2013) Sintering of Catalytic Nanoparticles: Particle Migration or Ostwald Ripening? Accounts of Chemical Research, 46, 1720-1730. https://doi.org/10.1021/ar3002427

[69] Granqvist, C.G. and Buhrman, R.A. (1976) Size Distributions for Supported Metal Catalysts: Coalescence Growth versus Ostwald Ripening. Journal of Catalysis, 42, 477-479. https://doi.org/10.1016/0021-9517(76)90125-1

[70] Lotty, O., Hobbs, R., O’Regan, C., Hlina, J., Marschner, C., O’Dwyer, C., Petkov, N. and Holmes, J.D. (2013) Self-Seeded Growth of Germanium Nanowires: Coalescence and Ostwald Ripening. Chemistry of Materials, 25, 215-222. https://doi.org/10.1021/cm3032863

[71] Weiss, J., Herrmann, N. and McClements, D. J. (1999) Ostwald Ripening of Hydrocarbon Emulsion Droplets in Surfactants Solutions. Langmuir, 15, 6652-6657. https://doi.org/10.1021/la981739d

[72] Smet, Y.D., Deriemaeker, L. and Finsy, R. (1999) Ostwald Ripening of Alkane Emulsions in the Presence of Surfactant Micelles. Langmuir, 15, 6745-6754. https://doi.org/10.1021/la9901736

[73] Rodriguez-Lopez, G., Williams, Y.O. and Toro-Mendoza, J. (2019) Individual and Collective Behavior of Emulsion Droplets Undergoing Ostwald Ripening. Langmuir, 35, 5316-5323. https://doi.org/10.1021/acs.langmuir.8b03959

[74] Wooster, T.J., Golding, M. and Sanguansri, P. (2008) Impact of Oil Type on Nanoemulsion Formation and Ostwald Ripening Stability. Langmuir, 24, 12758-12765. https://doi.org/10.1021/la801685v

[75] Finsy, R. (2004) On the Critical Radius in Ostwald Ripening. Langmuir, 20, 2975-2976. https://doi.org/10.1021/la035966d

[76] Lee, D.-K., Park, S.-I., Lee, J.K. and Hwang, N.-M. (2007) A Theoretical Model for Digestive Ripening. Acta Materialia, 55, 5281-5288.

https://doi.org/10.1016/j.actamat.2007.05.048

[77] Sahu, P. and Prasad, B.L.V. (2013) Fine Control of Nanoparticle Sizes and Size Distributions: Temperature and Ligand Effects on the Digestive Ripening Process. Nanoscale, 5, 1768-1771. https://doi.org/10.1039/C2NR32855K

[78] Sahu, P. and Prasad, B.L.V. (2012) Effect of Digestive Ripening Agent on Nanoparticle Size in the Digestive Ripening Process. Chemical Physics Letters, 525-526, 101-104. https://doi.org/10.1016/j.cplett.2011.12.078

[79] Shaik, A.H. and Chakraborty, J. (2015) Synthesis of Monodisperse Copper Nanoparticles using a Modified Digestive Ripening Technique and Formation of Superlattices. RSC Advances, 5, 85974-85977. https://doi.org/10.1039/C5RA16508C

[80] Yang, Y., Gong, X., Zeng, H., Zhang, L., Zhang, X., Zou, C. and Huang, S. (2010) Combination of Digestive Ripening and Seeding Growth as a Generalized Route for Precisely Controlling Size of Monodispersed Noble Monometallic, Shell Thickness of Core-Shell and Composition of Alloy Nanoparticles. Journal of Physical Chemistry $C, 114,256-264$. https://doi.org/10.1021/jp909065y

[81] Sidhaye, D.S. and Prasad, B.L.V. (2011) Many Manifestations of Digestive Ripening: 
Monodispersity, Superlattices and Nanomachining. New Journal of Chemistry, 35, 755-763. https://doi.org/10.1039/C0NJ00359I

[82] Sanyal, U., Datta, R. and Jagirdar, B.R. (2012) Colloidal Calcium Nanoparticles: Digestive Ripening in the Presence of a Capping Agent and Coalescence of Particles under an Electron Beam. RSC Advances, 2, 259-263.

https://doi.org/10.1039/C1RA00468A

[83] Shimpi, J.R., Chaudhari, V.R. and Prasad, B.L.V. (2018) Ligand-Solvent Compatibility: The Unsung Hero in the Digestive Ripening Story. Langmuir, 34, 13680-13689. https://doi.org/10.1021/acs.langmuir.8b02699

[84] Bhattacharya, C., Arora, N. and Jagirdar, B.R. (2019) Digestive-Ripening-Facilitated Nanoengineering of Diverse Bimetallic Nanostructures. Langmuir, 35, 6493-6505. https://doi.org/10.1021/acs.langmuir.8b02208

[85] Cingarapu, S., Yang, Z., Sorensen, C.M., Keith, H. and Klabunde, K.J. (2011) Synthesis of Indium Nanoparticles: Digestive Ripening under Mild Conditions. Inorganic Chemistry, 50, 5000-5005. https://doi.org/10.1021/ic200232b

[86] Prasad, B.L.V., Stoeva, S.I., Sorensen, C.M. and Klabunde, K.J. (2003) Digestive-Ripening Agents for Gold Nanoparticles: Alternatives to Thiols. Chemistry of Materials, 15, 935-942. https://doi.org/10.1021/cm0206439

[87] Shimpi, J.R., Sidhaye, D.S. and Prasad, B.L.V. (2017) Digestive Ripening: A Fine Chemical Machining Process on the Nanoscale. Langmuir, 33, 9491-9507. https://doi.org/10.1021/acs.langmuir.7b00193

[88] Sahu, P. and Prasad, B.L.V. (2014) Time and Temperature Effects on the Digestive Ripening of Gold Nanoparticles: Is There a Crossover from Digestive Ripening to Ostwald Ripening? Langmuir, 30, 10143-10150. https://doi.org/10.1021/la500914j

[89] Prasad, B.L.V., Stoeva, S.I., Sorensen, C.M. and Klabunde, K.J. (2002) Digestive Ripening of Thiolated Gold Nanoparticles: The Effect of Alkyl Chain Length. Langmuir, 18, 7515-7520. https://doi.org/10.1021/la020181d

[90] Shah, M., Badwaik, V., Kherde, Y., Waghwani, H.K., Modi, T., Aguilar, Z.P., Rodgers, H., Hamilton, W., Marutharaj, T., Webb, C., Lawrenz, M.B. and Dakshinamurthy, R. (2014) Gold Nanoparticles: Various Methods of Synthesis and Antibacterial Applications. Frontiers in Bioscience, 19, 1320-1344.

[91] Manzanares, J.A., Peljo, P. and Girault, H.H. (2017) Understanding Digestive Ripening of Ligand-Stabilized, Charged Metal Nanoparticles. Journal of Physical Chemistry C, 121, 13405-13411. https://doi.org/10.1021/acs.jpcc.7b04234

[92] Zhang, S., Zhang, L., Liu, K., Liu, M., Yin, Y. and Gao, C. (2018) Digestive Ripening in the Formation of Monodisperse Silver Nanospheres. Materials Chemistry Frontiers, 2, 1328-1333. https://doi.org/10.1039/C8QM00077H

[93] Sahu, P., Shimpi, J., Lee, H.J., Lee, T.R. and Prasad, B.L.V. (2017) Digestive Ripening of Au Nanoparticles Using Multidentate Ligands. Langmuir, 33, 1943-1950. https://doi.org/10.1021/acs.langmuir.6b03998

[94] Smetana, A.B., Klabunde, K.J., Sorensen, C.M., Ponce, A.A. and Mwale, B. (2006) Low-Temperature Metallic Alloying of Copper and Silver Nanoparticles with Gold Nanoparticles through Digestive Ripening. Journal of Physical Chemistry B, 110, 2155-2158. https://doi.org/10.1021/jp0539932

[95] Motl, N.E., Ewusi-Annan, E., Sines, I.T., Jensen, L. and Schaak, R.E. (2010) Au-Cu Alloy Nanoparticles with Tunable Compositions and Plasmonic Properties: Experimental Determination of Composition and Correlation with Theory. Journal of Physical Chemistry C, 114, 19263-19269. https://doi.org/10.1021/jp107637j 
[96] Bracey, C.L., Ellis, P.R. and Hutchings, G.J. (2009) Application of Copper-Gold Alloys in Catalysis: Current Status and Future Perspectives. Chemical Society Reviews, 38, 2231-2243. https://doi.org/10.1039/b817729p

[97] Wang, N., Han, Y., Xu, Y., Gao, C. and Cao, X. (2015) Detection of $\mathrm{H}_{2} \mathrm{O}_{2}$ at the Nanomolar Level by Electrode Modified with Ultrathin AuCu Nanowires. Analytical Chemistry, 87, 457-463. https://doi.org/10.1021/ac502682n

[98] Daniel, M.-C. and Astruc, D. (2004) Gold Nanoparticles: Assembly, Supramolecular Chemistry, Quantum-Size-Related Properties, and Applications toward Biology, Catalysis and Nanotechnology. Chemical Reviews, 104, 293-346. https://doi.org/10.1021/cr030698+

[99] Saha, K., Agasti, S.S., Kim, C., Li, X. and Rotello, V.M. (2012) Gold Nanoparticles in Chemical and Biological Sensing. Chemical Reviews, 112, 2739-2779.

https://doi.org/10.1021/cr2001178

[100] Gawande, M.B., Goswami, A., Felpin, F.-X., Asefa, T., Huang, X., Silva, R., Zou, X., Zboril, R. and Varma, R.S. (2016) $\mathrm{Cu}$ and $\mathrm{Cu}$-Based Nanoparticles: Synthesis and Applications in Catalysis. Chemical Reviews, 116, 3722-3811.

https://doi.org/10.1021/acs.chemrev.5b00482

[101] Zhang, D., Wang, R., Wen, M., Weng, D., Cui, X., Sun, J., Li, H. and Lu, Y. (2012) Synthesis of Ultralong Copper Nanowires for High-Performance Transparent Electrodes. Journal of the American Chemical Society, 134, 14283-14286. https://doi.org/10.1021/ja3050184

[102] Wang, Y. and Asefa, T. (2010) Poly(Allylamine)-Stabilized Colloidal Copper Nanoparticles: Synthesis, Morphology, and Their Surface-Enhanced Raman Scattering Properties. Langmuir, 26, 7469-7474. https://doi.org/10.1021/la904199f

[103] Salam, A.A., Singaravelan, R., Vasanthi, P. and Alwar, S.B. (2015) Electrochemical Fabrication of Ag-Cu Nano Alloy and Its Characterization: An Investigation. Journal of Nanostructure in Chemistry, 5, 383-392. https://doi.org/10.1007/s40097-015-0170-1

[104] Valodkar, M., Modi, S., Pal, A. and Thakore, S. (2011) Synthesis and Antibacterial Activity of $\mathrm{Cu}, \mathrm{Ag}$ and $\mathrm{Cu}-\mathrm{Ag}$ Alloy Nanoparticles: A Green Approach. Materials Research Bulletin, 46, 384-389. https://doi.org/10.1016/j.materresbull.2010.12.001

[105] Papaderakis, A., Mintsouli, I., Georgieva, J. and Sotiropoulos, S. (2017) Electrocatalysts Prepared by Galvanic Replacement. Catalysts, 7, 80. https://doi.org/10.3390/catal7030080

[106] Jing, H and Wang, H. (2015) Structural evolution of Ag-Pd Bimetallic Nanoparticles through Controlled Galvanic Replacement: Effects of Mild Reducing Agents. Chemistry of Materials, 27, 2172-2180.

https://doi.org/10.1021/acs.chemmater.5b00199

[107] Jenkins, S.V., Gohman, T.D., Miller, E.K. and Chen, J. (2015) Synthesis of Hollow Gold-Silver Alloyed Nanoparticles: A “Galvanic Replacement” Experiment for Chemistry and Engineering Students. Journal of Chemical Education, 92, 1056-1060. https://doi.org/10.1021/acs.jchemed.5b00042

[108] Collins, G., McCarty, E.K., and Holmes, J.D. (2015) Controlling Alloy Formation and Optical Properties by Galvanic Replacement of Sub-20 nm Silver Nanoparticles in Organic Media. Crystal Engineering Communications 17, 6999-7005. https://doi.org/10.1039/C5CE00659G

[109] Pal, A., Saha, S., Maji, S. K., Sahoo, R., Kundu, M. and Kundu, A. (2014) Galvanic Replacement of As(0) Nanoparticles by $\mathrm{Au}(\mathrm{III})$ for Nanogold Fabrication and SERS Application. New Journal of Chemistry, 38, 1675-1683. 
https://doi.org/10.1039/c3nj01489d

[110] Kalyan, I., Pal, T. and Pal, A. (2019) Time and Temperature Dependent Formation of Hollow Gold Nanoparticles via Galvanic Replacement Reaction of As(0) and Its Catalytic Application. MRS Communications, 9, 270-279. https://doi.org/10.1557/mrc.2018.214

[111] Pal, T., Jana, N.R. and Sau, T.K. (1997) Nucleophile Induced Dissolution of Gold. Corrosion Science, 39, 981-986. https://doi.org/10.1016/S0010-938X(97)00003-6

[112] Pande, S., Ghosh, S.K., Praharaj, S., Panigrahi, S., Basu, S., Jana, S., Pal, A., Tsukuda, T. and Pal, T. (2007) Synthesis of Normal and Inverted Gold-Silver Core-Shell Architectures in $\beta$-Cyclodextrin and Their Applications in SERS. Journal of Physical Chemistry C, 111, 10806-10813. https://doi.org/10.1021/jp0702393

[113] Henglein, A. and Brancewicz, C. (1997) Absorption Spectra and Reaction of Colloidal Bimetallic Nanoparticles Containing Mercury. Chemistry of Materials, 9, 2164-2167. https://doi.org/10.1021/cm970258x

[114] Toshima, N. and Wang, Y. (1994) Preparation and Catalysis of Novel Colloidal Dispersions of Copper/Noble Metal Bimetallic Clusters. Langmuir, 10, 4574-4580. https://doi.org/10.1021/la00024a031

[115] Daniel, J.R., McCarthy, L.A., Yazdi, S., Chagnot, M., Ringe, E. and Boudreau, D. (2018) Gold Speciation and Co-Reduction Control the Morphology of AgAu Nanoshells in Formaldehyde-Assisted Galvanic Replacement. Journal of Physical Chemistry C, 122, 18168-18176. https://doi.org/10.1021/acs.jpcc.8b05771

[116] Mallik, K., Mandal, M., Pradhan, N. and Pal, T. (2001) Seed Mediated Formation of Bimetallic Nanoparticles by UV Irradiation: A Photochemical Approach for the Preparation of "Core-Shell” Type Structures. Nano Letters, 1, 319-322. https://doi.org/10.1021/nl0100264

[117] Tsai, C.-H., Chen, S.-Y., Song, J.-M., Haruta, M. and Kurata, H. (2015) Effect of Ag Templates on the Formation of Au-Ag Hollow/Core-Shell Nanostructures. Nanoscale Research Letters, 10, Article No. 438. https://doi.org/10.1186/s11671-015-1141-7

[118] Pradhan, M., Chowdhury, J., Sarkar, S., Sinha, A.K. and Pal, T. (2012) Hierarchical Gold Flower with Sharp Tips from Controlled Galvanic Replacement Reaction for High Surface Enhanced Raman Scattering Activity. Journal of Physical Chemistry C, 116, 24301-24313. https://doi.org/10.1021/jp306330p

[119] Sasmal, A.K., Pal, J., Sahoo, R., Kartikeya, P., Dutta, S. and Pal, T. (2016) Superb Dye Adsorption and Dye-Sensitized Change in $\mathrm{Cu}_{2} \mathrm{O}-\mathrm{Ag}$ Crystal Faces in the Dark. Journal of Physical Chemistry C, 120, 21580-21588. https://doi.org/10.1021/acs.jpcc.6b07300

[120] Shon, Y.-S., Dawson, G.B., Porter, M. and Murray, R.W. (2002) Monolayer-Protected Bimetal Cluster Synthesis by Core Metal Galvanic Exchange Reaction. Langmuir, 18, 3880-3885. https://doi.org/10.1021/la025586c

[121] Petri, M.V., Ando, R.A. and Camargo, P.H.C. (2012) Tailoring the Structure, Composition, Optical Properties and Catalytic Activity of Ag-Au Nanoparticles by the Galvanic Replacement Reaction. Chemical Physics Letters, 531, 188-192. https://doi.org/10.1016/j.cplett.2012.02.039

[122] Sun, Y., Mayers, B. T. and Xia, Y. (2002) Template-Engaged Replacement Reaction: A One-Step Approach to the Large-Scale Synthesis of Metal Nanostructures with Hollow Interiors. Nano Letters, 2, 481-485. https://doi.org/10.1021/nl025531v

[123] He, W., Wu, X., Liu, J. Zhang, K., Chu, W., Feng, L., Hu, X., Zhou, W. and Xie, S. (2010) Formation of AgPt Alloy Nanoislands via Chemical Etching with Tunable 
Optical and Catalytic Properties. Langmuir, 26, 4443-4448. https://doi.org/10.1021/la9034968

[124] Alivio, T.E.G., Fleer, N.A., Singh, J., Nadadur, G., Feng, M., Banerjee, S. and Sharma, V.K. (2018) Stabilization of Ag-Au Bimetallic Nanocrystals in Aquatic Environments Mediated by Dissolved Organic Matter: A Mechanistic Perspective. Environmental Science and Technology, 52, 7269-7278.

https://doi.org/10.1021/acs.est.8b01003

[125] Nafria, R., Genç, A., Ibáñez, M., Arbiol, J., Ramírez de la Piscina, P., Homs, N. and Cabot, A. (2016) Co-Cu Nanoparticles: Synthesis by Galvanic Replacement and Phase Rearrangement during Catalytic Activation. Langmuir, 32, 2267-2276. https://doi.org/10.1021/acs.langmuir.5b04622

[126] Bastos-Arrieta, J., Muñoz, J., Vigués, N., Muraviev, D.N., Céspedes, F., Mas, J., Baeza, M. and Muñoz, M. (2016) Intermatrix Synthesis of Ag, AgAu and Au Nanoparticles by Galvanic Replacement Strategy for Bactericidal and Electrocatalytically Active Nanocomposites. New Journal of Chemistry, 40, 10344-10352. https://doi.org/10.1039/C6NJ02468H

[127] Thota, S., Chen, S. and Zhao, J. (2016) An Unconventional Mechanism of Hollow Nanorod Formation: Asymmetric Cu Diffusion in $\mathrm{Au}-\mathrm{Cu}$ Alloy Nanorods during Galvanic Replacement Reaction. Chemical Communications, 52, 5593-5596. https://doi.org/10.1039/C6CC00752I

[128] Xia, X., Wang, Y., Ruditskiy, A. and Xia, Y. (2013) Galvanic Replacement: A Simple and Versatile Route to Hollow Nanostructures with Tunable and Well-Controlled Properties. Advanced Materials, 25, 6313-6333. https://doi.org/10.1002/adma.201302820

[129] Zhang, Z., Zhang, J., Thenuwara, A. C., Strongin, D. R., Sun, Y. and Ren, S. (2018) Structure and Magnetism Evolution from FeCo Nanoparticles to Hollow Nanostructure Conversion for Magnetic Applications. ACS Applied Nano Materials, 1, 5837-5842. https://doi.org/10.1021/acsanm.8b01488

[130] Lv, L., Li, Z., Xue, K. H., Ruan, Y., Ao, X., Wan, H., Miao, X., Zhang, B., Jiang, J., Wang, C. and Ostrikov, K. (2018) Tailoring the Electrocatalytic Activity of Bimetallic Nickel-Iron Diselenide Hollow Nanochains for Water Oxidation. Nano Energy, 47, 275-284. https://doi.org/10.1016/j.nanoen.2018.03.010

[131] El Mel, A.-A., Nakamura, R. and Bittencourt, C. (2015) The Kirkendall Effect and Nanoscience: Hollow Nanospheres and Nanotubes. Beilstein Journal of Nanotechnology, 6, 1348-1361. https://doi.org/10.3762/bjnano.6.139

[132] Wang, W., Dahl, M. and Yin, Y. (2013) Hollow Nanocrystals through the Nanoscale Kirkendall Effect. Chemistry of Materials, 25, 1179-1189. https://doi.org/10.1021/cm3030928

[133] Nakajima, H. (1997) The Discovery and Acceptance of the Kirkendall Effect: The Result of a Short Research Career. JOM, 49, 15-19. https://doi.org/10.1007/BF02914706

[134] Kirkendall, E., Thomassen, L. and Upthegrove, C. (1939) Rates of Diffusion of Copper and Zinc in Alpha Brass. Transactions of the Metallurgical Society of AIME, 133, 186-203. https://ci.nii.ac.jp/naid/10002957240/

[135] Anderson, B.D. and Tracy, J.B. (2014) Nanoparticle Conversion Chemistry: Kirkendall Effect, Galvanic Exchange and Anion Exchange. Nanoscale, 6, 12195-12216. https://doi.org/10.1039/C4NR02025A

[136] Pal, T., Sau, T.K. and Jana, N.R. (1997) Reversible Formation and Dissolution of Silver Nanoparticles in Aqueous Surfactant Media. Langmuir, 13, 1481-1485. 
https://doi.org/10.1021/la960834o

[137] Sau, T.K., Pal, A. and Pal, T. (2001) Size Regime Dependent Catalysis by Gold Nanoparticles for the Reduction of Eosin. Journal of Physical Chemistry B, 105, 9266-9272. https://doi.org/10.1021/jp011420t

[138] Pande, S., Sarkar, A.K., Basu, M., Jana, S., Sinha, A.K., Sarkar, S., Pradhan, M., Saha, S., Pal, A. and Pal, T. (2008) Gram-Level Synthesis of Lead-Free Solder in the Nanometer Length Scale Obtained from Tin and Silver Compounds Using Silicone Oil. Langmuir, 24, 8991-8997. https://doi.org/10.1021/la8011662

[139] Xi, Y., Zu, F.-Q., Liu, L.-J., Shen, R.-R., Li, X.-F. and Chen, Z.-H. (2005) Abnormal Solidification of $\mathrm{Pb}-\mathrm{Sn}$ Alloy Induced by Liquid Structure Transition. Kovové Materiály, 43, 432-439.

[140] Sinha, A.K., Sasmal, A.K., Mehetor, S.K., Pradhan, M. and Pal, T. (2014) Evolution of Amorphous Selenium Nanoballs in Silicone Oil and their Solvent Induced Morphological Transformation. Chemical Communications, 50, 15733-15736. https://doi.org/10.1039/C4CC08168D

[141] Guo, S. and Liu, C. T. (2011) Phase Stability in High Entropy Alloys: Formation of Solid-Solution Phase and Amorphous Phase. Progress in Natural Science: Materials International, 21, 433-446. https://doi.org/10.1016/S1002-0071(12)60080-X

[142] Wu, Z., Guo, J., Liang, Z., Zhang, Y., Ye, X., Zhang, J., Li, Y., Liu, Y. and Yang, H. (2020) Room Temperature Metamagnetic Transformation of a Tough Dual-Phase Ni-Mn-Sn-Fe Ferromagnetic Shape Memory Alloy. Journal of Alloys and Compounds, 829, Article ID: 154606.https://doi.org/10.1016/j.jallcom.2020.154606

[143] Mouritz, A.P. (2012) Titanium Alloys for Aerospace Structure and Engines. In: Mouritz, A.P., Introduction to Aerospace Materials, Woodhead Publishing Limited, Cambridge, UK, 202-223. https://doi.org/10.1533/9780857095152.202

[144] Körösy, G., Tomolya, K., Janovszky, D. and Sólyom, J. (2013) Evolution of XRD Analysis of Amorphous Alloy. Materials Science Forum, 729, 419-423. https://doi.org/10.4028/www.scientific.net/MSF.729.419 